\title{
THE ROLE OF FOLLICULAR-SECRETED FACTORS IN THE MAINTENANCE OF MEIOTIC ARREST IN RATS
}

\section{ZARAMASINA LENA CLARK}

\author{
A thesis submitted to \\ Victoria University of Wellington \\ in partial fulfilment of the requirements for the degree of \\ Master of Biomedical Science
}

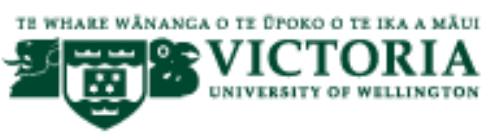

Victoria University of Wellington

Te Whare Wānanga o te Ūpoko o te Ika a Mãui 2014 



\section{ABSTRACT}

Meiosis is the process by which diploid germ cells develop into competent haploid gametes. In female mammals, meiosis is characterised by two periods of arrest, the duration of which is species-specific. This study investigated the first period of meiotic arrest which occurs at the diplotene stage of prophase I. This period of arrest has important implications for artificial reproductive technologies as the maintenance of meiotic arrest in the in vitro situation has been correlated with improved embryological outcomes. Despite there being extensive evidence that the somatic cells of the follicle (granulosa and cumulus cells) produce meiosis-inhibiting factors, the factors themselves and the mechanisms through which they act are unclear. Recent evidence implicates C-type natriuretic peptide (CNP) and oestradiol in the regulation of meiotic arrest in mouse oocytes. In this proposed hypothesis, CNP is produced by the granulosa cells and activates its cognate receptor, NPR2, on cumulus cells. This results in the production of cyclic guanosine monophosphate (cGMP) in cumulus cells which is transferred to the oocyte via gap junctions. In the oocyte, CGMP slows the rate of hydrolysis of cyclic adenosine monophosphate (cAMP) by phosphodiesterase 3A resulting in elevated intra-oocyte cAMP levels. By maintaining high levels of cAMP in the oocyte, maturation-promoting factor (MPF) activity is inhibited, preventing re-entry into the cell cycle, thus maintaining meiotic arrest. The overall objective of this study was to investigate the validity of this aforementioned hypothesised regulatory pathway in another mammalian species, the rat. Four fundamental components of this pathway were chosen to be investigated and these framed the four aims of this study.

The aims of this study were to investigate in cultured rat cumulus cell-oocyte complexes (COCs) the short and long-term effects of CNP and oestradiol, both alone and in combination on (1) gap junction permeability using a validated gap junction assay, (2) intracellular cGMP levels using a direct competitive immunoassay, (3) mRNA expression levels of key cumulus cell-derived genes (Npr2, the receptor for CNP; and Pde4b and Pde4d, phosphodiesterases) using an optimised multiplex TaqMan qPCR reaction, and (4) duration of meiotic arrest. 
Overall, the results of this study indicated that the assessed treatments did not alter gap junction permeability in rat COCs in vitro. Whilst treatment with CNP and oestradiol appeared to increase the intracellular levels of cGMP in COCs, this requires further investigation. Notably, this study confirmed the role of steroid hormones in upregulating Npr2 expression. Indirect evidence suggests that PDE4D in particular, is a major regulator of cyclic nucleotide levels in the cumulus cells. Finally, treatment of rat COCs with CNP and oestradiol increased the duration of meiotic arrest in oocytes incubated in vitro.

The results of this study provide the first evidence that the hypothesised regulatory pathway proposed above is also relevant in the rat. Nonetheless, further investigation of the effects of CNP and oestradiol on the modulation of intracellular cGMP levels are required to fully validate the model. 


\section{ACKNOWLEDGEMENTS}

Firstly, I would like to thank my supervisors, Dr Janet Pitman and Prof Ken McNatty, for the opportunity to work on a project that has been both challenging and rewarding. Throughout the past two years, Janet has been patient, supportive and encouraging and for this I would like to thank her. My experience working under her supervision is one of the major reasons that I chose to pursue further study and for this I will always be grateful. Ken's input into this project has been invaluable. I would like to thank Ken for taking the time to make sure I understood important concepts and key aspects of my project, and for giving me the chance to become a part of this lab group.

I would like to express my gratitude to Richard Moore, Peter Vancompernolle, and Dr Bronwyn Kivell who supplied the female rats used in my experiments and to Peter Johnstone for his assistance in analysing the GPCR data.

To all the members of the Reproduction group, thank you for your friendship, for teaching me everything I know about working in a lab and for making it all so enjoyable. In particular I would like to thank Adrian Bibby for his assistance with tissue collection without which I might still be working, Norma Hudson for her invaluable expertise and in particular for teaching me the orcein staining protocol and Kelly for teaching me the gap junction assay. Catherine and Shalen, thank you for your friendship and for your support especially during the many long nights in the lab.

This is the perfect opportunity for me to acknowledge the support of the Te Rōpū Āwhina whānau. Malo 'aupito Liz and Vivian for your support and your belief in my potential even when I was unsure.

At this point, I would also like to thank the Pacific Islands Polynesian Education Fund for their support in the form of the PIPEF Post-Graduate Scholarship.

Last but definitely not least, I would like to thank my family and friends. I'd especially like to acknowledge my parents, brothers and sister, all of my aunties and Nena for their love and unfailing belief in me. None of this could have been possible without you. Thank you for understanding when I couldn't make it to things, when I was absent minded and when you had to wait. 'Ofa lahi atu. 


\section{TABLE OF CONTENTS}

ABSTRACT

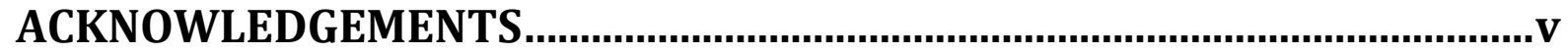

LIST OF FIGURES

LIST OF TABLES

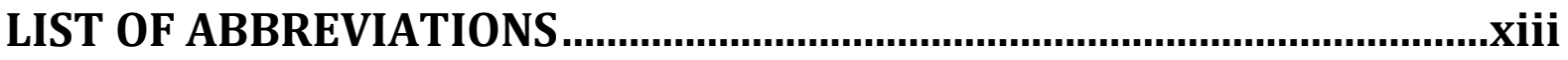

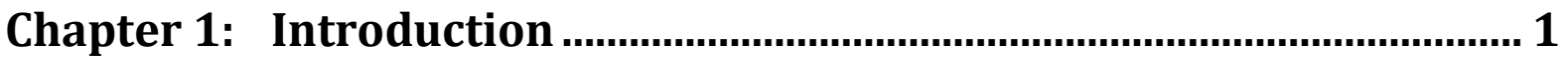

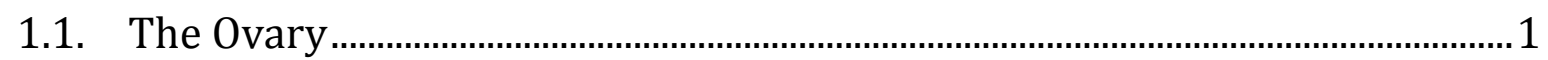

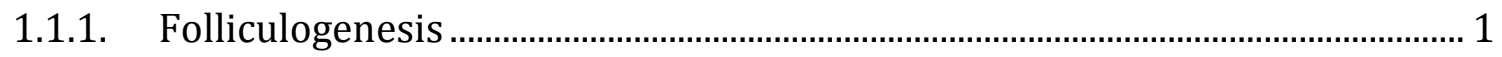

1.1.2. Meiosis and Meiotic Arrest.................................................................................... 4

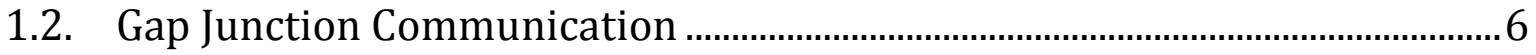

1.3. Cyclic Nucleotides and Phosphodiesterases in the Follicle .............................. 8

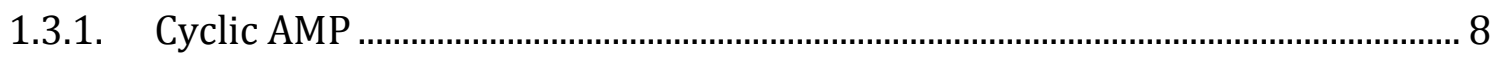

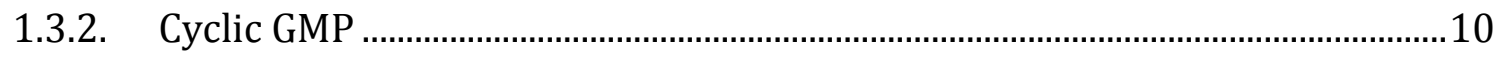

1.3.3. Phosphodiesterases and the Regulation of Follicular Cyclic Nucleotide

Levels

1.4. Follicular-secreted Factors involved in the Maintenance of Meiotic

Arrest in vitro

1.4.1. C-Type Natriuretic Peptide (CNP) and Natriuretic Peptide Receptor 2

(NPR2)

1.4.2. The Role of Steroid Hormones in CNP/NPR2 Signalling... .14 
1.4.3. The Role of CNP/NPR2 Signalling in the Maintenance of Meiotic Arrest in Mice

1.5. Species Differences in the Regulation of Meiotic Arrest.

1.6. The Overall Objectives and Aims 18

Chapter 2: Materials and Methods …......................................................20

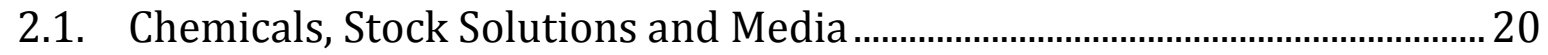

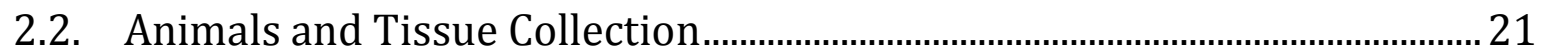

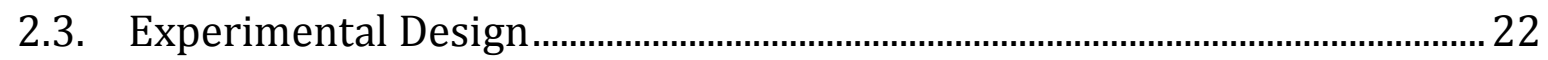

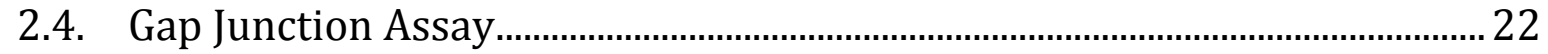

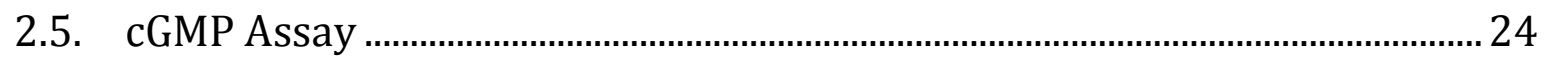

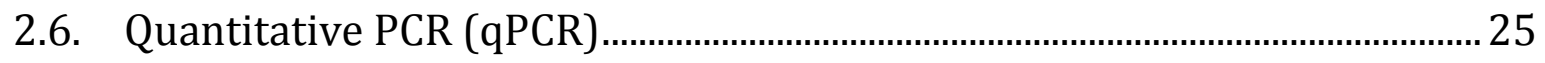

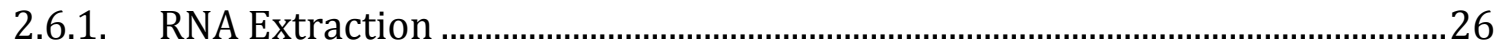

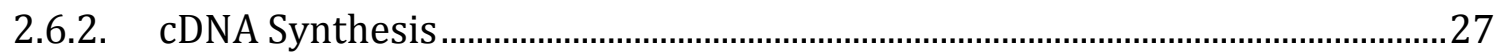

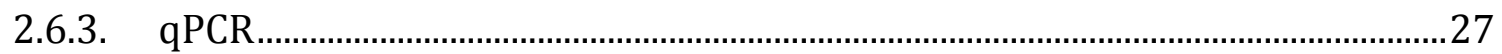

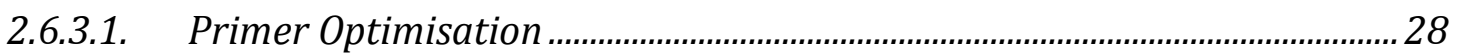

2.6.3.2. Probe Optimisation and qPCR Sample Analysis............................................2 29

2.6.3.3. Multiplex Optimisation ..................................................................................... 30

2.7. Assessment of GVBD and Orcein Staining ........................................................ 31

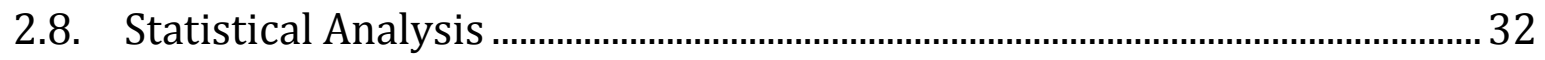




\subsection{The Effect of Phosphodiesterase Inhibitors (Dipyradimole and}

Rolipram) on Gap Junction Communication and the Duration of Meiotic

Arrest in rat COCs Cultured in vitro

3.1.1. The Effects of Phosphodiesterase Inhibitors on Gap Junction

Communication in Rat COCs cultured in vitro 34

3.1.2. The Effects of Phosphodiesterase Inhibitors on GVBD in Rat COCs cultured in vitro 35

3.2. The Effects of Increasing doses of C-Type Natriuretic Peptide (CNP), Oestradiol and Progesterone on the Duration of Meiotic Arrest in Rat COCs Cultured in vitro

3.2.1. The Effects of Increasing Doses of CNP on GVBD in Rat COCs cultured in vitro

3.2.2. The Effects of Increasing Doses of Oestradiol on GVBD in Rat COCs cultured in vitro 37

3.2.3. The Effects of Increasing Doses of Progesterone on GVBD in Rat COCs cultured in vitro

3.3. Outcomes from Optimisation Studies

\section{Chapter 4: Results -The Effects of C-Type Natriuretic Peptide (CNP)} and Steroid Hormones on CNP/NPR2 signalling in Rat COCs cultured in vitro

4.1. The Effects of Follicular-secreted Factors on Gap Junction

Communication in Rat COCs cultured in vitro 40 
4.2. The Effects of CNP and Oestradiol on cGMP levels in COCs cultured in

vitro

4.3. The Effects of CNP and Steroid Hormone Treatments on Cumulus

Cell-Derived Gene Expression in Rat COCs Cultured in vitro 43

4.3.1. The Effects of CNP and Steroid Hormone Treatments on Npr2 mRNA Expression in Rat Cumulus Cells

4.3.2. The Effects of CNP and Steroid Hormones on Pde4d mRNA expression in Rat Cumulus Cells 44

4.4. The Effect of CNP and Steroid Hormones on GVBD in Rat COCs

cultured in vitro .46

4.4.1. The Effect of CNP and Oestradiol on the Duration of Meiotic Arrest without Phosphodiesterase Inhibitor Supplementation.

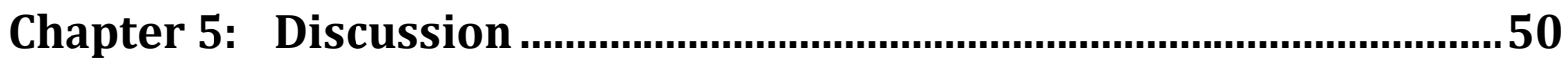

Chapter 6: Conclusions and Future Directions .......................................57

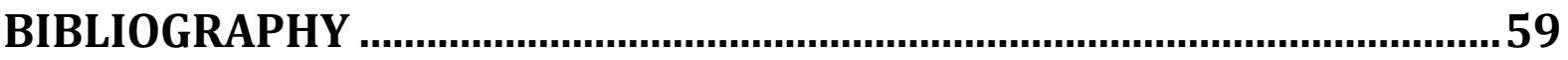




\section{LIST OF FIGURES}

Figure 1-1: The stages of folliculogenesis ..................................................... 2

Figure 1-2: The stages of meiosis in relation to developmental events in female mice................................................................................... 5

Figure 1-3: Photomicrographs of denuded rat oocytes with (A) and without (B) a germinal vesicle (GV) ........................................................... 6

Figure 1-4: The formation and structure of gap junctions.................................. 8

Figure 1-5: The hypothesised regulatory mechanism for meiotic arrest in the

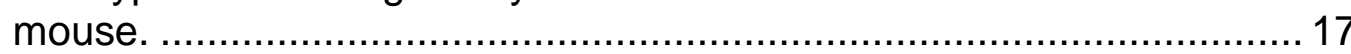

Figure 3-1: Fluorescent dye transfer measured in denuded oocytes following culture of rat COCs with or without phosphodiesterase inhibitors (DR) for 1,5 or 19 hours. ..................................................................... 34

Figure 3-2: The proportion of rat oocytes that had initiated GVBD following culture in the presence (DR) or absence (control) of phosphodiesterase inhibitors for 1,5 or 19 hours.

Figure 3-3: The proportion of oocytes that had initiated GVBD following the culture of rat COCs with 0 (control), 1, 10 or $100 \mathrm{nM} \mathrm{CNP}$ for 4 or 18 hours.

Figure 3-4: The proportion of oocytes that had initiated GVBD following the culture of rat COCs with 0 (control), 50,200 or $1000 \mathrm{ng} / \mathrm{mL}$ oestradiol for 4 or 18 hours.

Figure 3-5: The proportion of oocytes that had initiated GVBD following the culture of rat COCs with 0 (control), 50,200 or $1000 \mathrm{ng} / \mathrm{mL}$ progesterone for 4 or 18 hours.

Figure 4-1: Mean fluorescent values \pm SEM in oocytes following in vitro culture of rat COCs with media alone (control), CNP, oestradiol, CNP and oestradiol in combination, and CNP and progesterone in combination for either 1,5 or 19 hours.

Figure 4-2: The levels of cGMP (fmole) per COC following in vitro culture of rat COC pools (100 COCs) with CNP and oestradiol, alone and in combination for 5 hours.

Figure 4-3: Mean relative mRNA expression levels \pm SEM of Npr2 in cumulus cells of rat COCs incubated with media alone (control), CNP, oestradiol, CNP and oestradiol in combination, and CNP and progesterone in combination for either 1,5 or 19 hours.

Figure 4-4: Mean relative mRNA expression levels \pm SEM of $P d e 4 d$ in cumulus cells of rat COCs incubated with media alone (control), CNP, oestradiol, CNP and oestradiol in combination, and CNP and progesterone in combination for either 1,5 or 19 hours.

Figure 4-5: Mean proportions (\%) \pm SEM of rat oocytes with or without (GVBD) a visible germinal vesicle in rat COCs incubated with media alone (control), CNP, oestradiol, CNP and oestradiol in combination, and CNP and progesterone in combination for either 1, 5 or 19 hours.

Figure 4-6: Mean proportions (\%) \pm SEM of rat oocytes with or without (GVBD) a visible germinal vesicle of rat COCs that were assessed immediately following collection, or following a 5 hour incubation with media alone (control), or CNP and oestradiol in combination. 
Figure 4-7: Photomicrographs of denuded rat oocytes in the germinal vesicle (GV) stage stained with orcein.

Figure 4-8: Photomicrographs of denuded rat oocytes that have initiated germinal vesicle breakdown (GVBD). 


\section{LIST OF TABLES}

Table 2-1: NCBI Accession numbers and nucleotide sequences for the TaqMan probe and forward $(F)$ and reverse $(R)$ primers for the genes

investigated in this study.

Table 2-2: Final optimised forward and reverse primer and TaqMan probe concentrations (nM) that were used in the quadriplex APCR reactions.

Table 2-3: The amplication efficiency for each of the genes in the multiplex qPCR reactions. 


\section{LIST OF ABBREVIATIONS}

8-br-cAMP

AM

ANOVA

ANP

BMP15

BNP

CAMP

$\mathrm{CC}$

cDNA

cGMP

CNP

$\mathrm{CO}_{2}$

$\mathrm{COC}$

$\mathrm{C}_{\mathrm{q}}$

CV

dbcAMP

DES

$\mathrm{dH}_{2} \mathrm{O}$

DMSO

DO

dpc

DR

$\mathrm{E}_{2}$

Esr2

FGF-8B

$\mathrm{FSH}$

GC

GDF9

GJ

GJA

GJC

GPR/GPCR 8-bromoadenosine cyclic monophosphate

Acetoxymethyl

Analysis of variance

Atrial natriuretic peptide

Bone morphogenetic protein 15

Brain natriuretic peptide

Cyclic adenosine monophosphate

Cumulus cells

Complimentary deoxyribonucleic acid

Cyclic guanosine monophosphate

C-type natriuretic peptide

Carbon dioxide

Cumulus-oocyte complex

Threshold cycle (referred to as $\mathrm{C}_{\mathrm{T}}$ in the past)

Coefficient of variation

Dibutryl cAMP

Diethylstilboestrol

Distilled water

Dimethyl sulfoxide

Denuded oocyte

Days post-coitum

Dipyradimole and rolipram PDE inhibitor solution

$17 \beta$-oestradiol

Oestrogen receptor $2 / \beta$ gene

Fibroblast growth factor $8 \mathrm{~B}$

Follicle-stimulating hormone

Guanylyl cyclase receptors

Growth differentiation factor 9

Gap junction

Gap junction assay

Gap junction communication

G-protein coupled receptor 
GV

GVBD

hCG

IBMX

MPF

mRNA

NPPC

NPR

OSF

$\mathrm{P}_{4}$

PBS

PDE

SEM

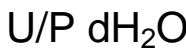

Germinal vesicle

Germinal vesicle breakdown

Human chorionic gonadotropin

3-isobutyl-1-methylxanthine

Maturation-promoting factor

Messenger ribonucleic acid

Natriuretic precursor peptide C

Natriuretic peptide receptor

Oocyte-secreted factor

Progesterone

Phosphate-buffered saline

Phosphodiesterase

Standard error of the mean

Ultra-pure distilled water 


\section{Chapter 1: Introduction}

\subsection{The 0vary}

The mammalian ovary has two main functions. Firstly, it is the organ within which the female gamete, the oocyte, develops and matures. Secondly, the ovaries are a major endocrine gland, producing a number of hormones and regulatory proteins, including $17 \beta$-oestradiol and progesterone, which have a plethora of local and systemic effects. These functions are not independent of each other as the hormones produced by the ovary are required for the latter stages of oocyte maturation and are instrumental in regulating the recruitment of growing follicles, and the induction of follicular growth, follicle maturation and ovulation.

The ovaries are a pair of ductless glands that are located on either side of the uterus in female mammals. The ovary is comprised of two regions (cortex and medulla) that differ in function (Tortora, 2003). The ovarian follicles are located in the cortex which is encapsulated by the surface epithelium. The medulla is located in the centre of the ovary and is comprised of dense connective tissue as well as blood and lymphatic vessels, and nerves.

\subsubsection{Folliculogenesis}

In those species (e.g. humans, mice and sheep) in which this has been rigorously studied, it has been revealed that the primordial germ cells migrate to the gonadal ridge during embryogenesis (Chiquoine, 1954; Zamboni et al., 1979). Upon reaching the prospective gonad, the primordial germ cells differentiate into oogonia and form germ cell clusters within isolated regions termed ovigerous cords. Within these ovigerous cords, oogonia substantially increase their numbers by mitosis and primitive granulosa cells are recruited from the ovarian surface epithelium to associate with these proliferating oogonia. During this time, oogonia are also undergoing either apoptosis or initiation of meiosis. The healthy oogonia that enter meiosis and subsequently arrest at the prophase stage of meiosis I are termed oocytes. Each oocyte is surrounded by a complement of granulosa cells and bud off from the base of the ovigerous cords. The formation of these non-growing primordial follicles marks the beginning of folliculogenesis (Braw-Tal, 2002; Sawyer et al., 2002; van den Hurk and Zhao, 2005). 


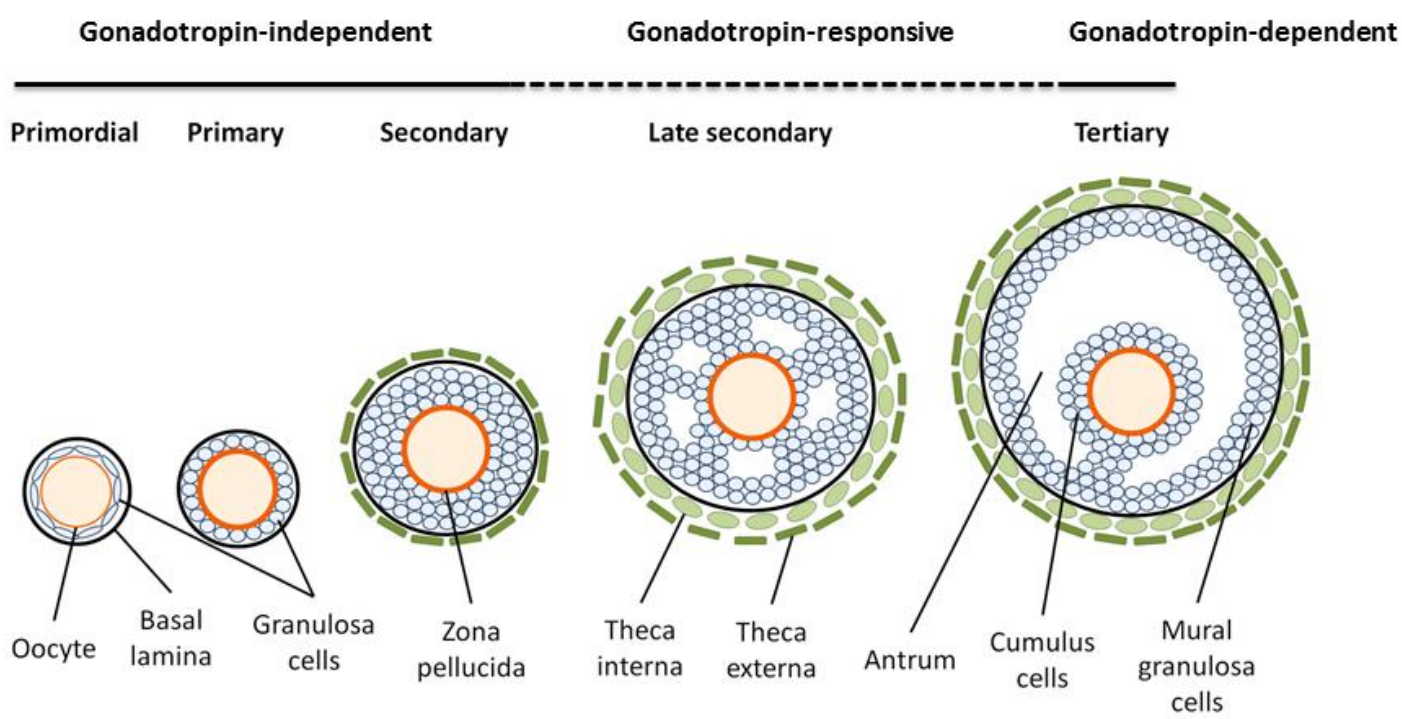

Figure 1-1: The stages of folliculogenesis, including the formation of the antrum and the gonadotropin-independent, gonadotropin-responsive and gonadotropin-dependent phases.The transition from the pre-antral to the antral stages of follicular growth also marks the transition after which the oocyte has the ability to attain meiotic competence. That is, removal of the oocyte from these follicles results in spontaneous meiotic resumption, as is the case during in vitro culture. Modified from a diagram supplied by Lisa Johnston. (VUW BBMedSci Honours thesis, 2010).

The initiation of follicular growth is marked by a change in cell morphology as the granulosa cells surrounding the oocyte within primordial follicles change from squamous to cuboidal in shape. Following this transition, the follicle is now termed a primary follicle. Recruitment to the pool of growing follicles is a continuous process that is dependent on the order in which follicles are formed. The first follicles that are formed, are the first to begin growing and they grow continuously until they die or ovulate (Edwards et al., 1970). This process of recruitment and growth begins coincidently with the formation of primordial follicles (Edwards et al., 1970) and in women and other species, this process continues until this finite pool of follicles is exhausted (Peters et al., 1975; Richardson et al., 1987).

In response to paracrine signals from the oocyte, such as oocyte-secreted factors (OSF), the granulosa cells of a primary follicle proliferate to form multiple layers surrounding the oocyte, an event that marks the transition to a secondary follicle (Figure 1-1) (Yang and Fortune, 2008). The oocyte is thought to dictate this transition. Evidence for this includes reports of oocytes that were removed from secondary follicles and inserted into primordial follicles and these have been found to increase the rate of follicular development to the extent that these primordial follicles appeared morphologically similar to secondary oocytes (Eppig et al., 2002). Two 
OSF, namely growth differentiation factor 9 (GDF-9) and bone morphogenetic protein 15 (BMP-15) have been shown to stimulate proliferation and differentiation of the granulosa cells which is essential for normal follicular development in some species (Hayashi et al., 1999; Eppig et al., 2002).

The majority of oocyte growth is completed during the pre-antral stages in secondary follicles and subsequent formation of a fluid-filled antrum is heavily influenced by the oocyte. As the number of granulosa cells increase, small fluid-filled spaces begin to form between the granulosa cells and these coalesce to form a large fluid-filled cavity (Hirshfield, 1991). Antral or follicular fluid is hypothesised to be a product of an osmotic gradient generated by the production and secretion of hyaluron and versican by the granulosa cells and results in increased fluid accumulation and retention in the follicle (Rodgers and Irving-Rodgers, 2010). Antrum development results in the differentiation of the homogenous granulosa cell population into two distinct populations, the mural granulosa cells and the cumulus cells (Figure 1-1) (Sugiura and Eppig, 2005). The mural granulosa cells are mainly involved in steroidogenesis whilst the cumulus cells remain associated with the oocyte to provide substrates and metabolites critical for oocyte maturation (Armstrong et al., 1996; Carabatsos et al., 2000).

The formation of the antrum also indicates a transition from the gonadotropinindependent phase to the gonadotropin-responsive and then gonadotropindependent phase of follicular development (Scaramuzzi et al., 1993; Edson et al., 2009; Sirard, 2011; Zhang and Xia, 2011). Without the appropriate stimulation by pituitary-derived follicle-stimulating hormone (FSH) and luteinising hormone (LH), the fate of the gonadotropin-dependent follicles is atresia. Thus sexual maturation and puberty are essential milestones that must be attained before folliculogenesis can be completed (i.e. development from primordial follicles to the ovulation of a mature oocyte). Puberty coincides with neuronal development in the hypothalamus that results in the hormonal interplay between the pituitary gland and the ovaries in all reproductively-active mammals. In all mammals, the late luteal or initial follicular phase of the oestrous cycle is dominated by high concentrations of FSH that supports the growth of antral follicles, however, this declines due to increasing follicular oestradiol production. The increasing levels of oestradiol eventually lead to 
the stimulation of a pre-ovulatory surge of $\mathrm{LH}$ which triggers ovulation in the preovulatory follicle(s).

\subsubsection{Meiosis and Meiotic Arrest}

The development of competent haploid gametes (i.e. oocyte or spermatozoa) from diploid germ cells (i.e. oogonia or spermatogonia) occurs by the process of meiosis (Figure 1-2). In female mammals, the process of meiosis is characterised by long periods of arrest. The first of which begins during foetal development when oocytes enter the diplotene stage of prophase I and this arrested stage of maturation is maintained, even in growing follicles, until just prior to ovulation when the preovulatory LH surge occurs (Sirard, 2001; Mehlmann, 2005a; Zhang and Xia, 2011). The duration of the first meiotic arrest is species-specific and dependent upon the timing of puberty and life expectancy of each species or in those species that undergo menopause, the timing of depletion of the ovarian follicular reserve. Consequently in women, some oocytes may be in meiotic arrest for approximately 40 years (Tripathi et al., 2010). In most species, there are two periods of meiotic arrest. Following the resumption of meiosis from the diplotene stage of prophase I, the second arrest occurs at metaphase II. Meiotic resumption after this point is dependent on successful fertilization of the oocyte (Whitaker, 1996). Oocytes that are in meiotic arrest at the diplotene stage of prophase I are morphologically identifiable when viewed under a microscope due to the presence of the germinal vesicle (GV; Figure 1-3). The GV is the visible nuclear membrane which contains partially-condensed chromosomes and a prominent nucleolus (Zhang and Xia, 2011). Breakdown of the GV (GVBD) is considered an endpoint marker of the completion of nuclear maturation in the oocyte and the cessation of meiotic arrest (Mehlmann, 2005a; Zhang and Xia, 2011). At meiotic resumption, prophase I is completed and extrusion of the first polar body occurs. 


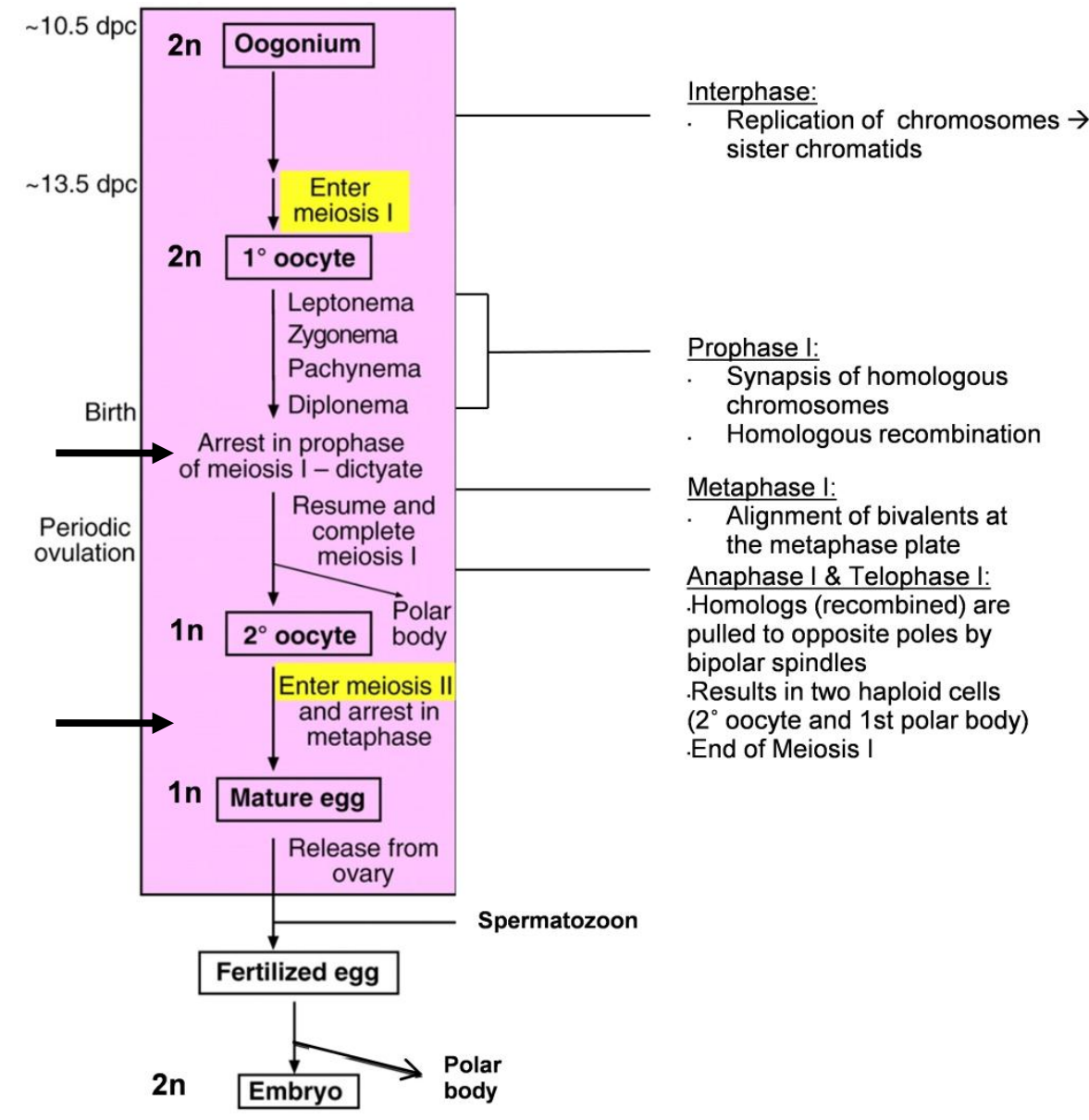

Figure 1-2: The stages of meiosis in relation to developmental events in female mice. Key events during the stages of meiosis I are described in relation to days post-coitum (dpc) and the two periods of meiotic arrest are indicated by black arrows. This diagram also describes changes in chromosome number that occur during meiosis. A reductive division at the end of meiosis I result in the haploid (1n) oocyte and extrusion of the first polar body $(n-$ the number of chromosomes, in the mouse $n=20$ and rat $n=21$ ). (Modified from Bowles and Koopman, 2007.)

It is during the antral phase of follicular development that oocytes acquire meiotic competence, defined as the ability to resume meiosis spontaneously when removed from the follicular environment (Mehlmann, 2005a). Interestingly, oocytes from antral follicles, but not primordial and primary follicles (Mehlmann, 2005a), will undergo spontaneous meiotic resumption when removed from the follicular compartment and cultured in vitro. As such, it has been hypothesised that the follicle and in particular, the somatic cells (the granulosa and cumulus cells) of the follicle play a key role in the maintenance of meiotic arrest, through the production of meiosis-inhibiting factors (Pincus and Enzmann, 1935). 


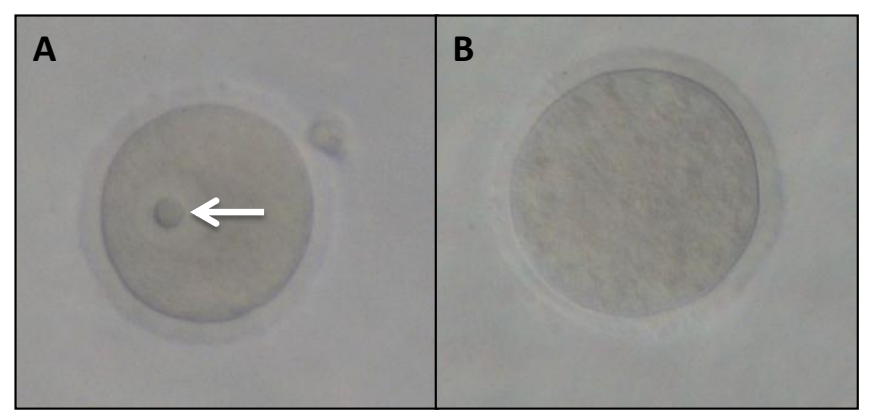

Figure 1-3: Photomicrographs of denuded rat oocytes with $(A)$ and without $(B)$ a germinal vesicle (GV). The oocyte in A has a clearly visible GV, as indicated by the white arrow. Conversely there is no visible GV in the oocyte in B, indicating the initiation of GV breakdown.

\subsection{Gap Junction Communication}

The somatic cells of the follicle are physically and metabolically coupled to each other and the oocyte by gap junctions. These gap junctions are involved in supplying essential ions, amino acids and metabolites $(<1000 \mathrm{kDa})$ to the oocyte. In addition, gap junctions are involved in the transport of other regulatory molecules, including cyclic adenosine monophosphate (CAMP) and cyclic guanosine monophosphate (cGMP) which have been shown to be essential for the maintenance of meiotic arrest (Gilchrist et al., 2008). The cumulus-oocyte complex (COC) contains both homologous (between the somatic cells) and heterologous (between the somatic cells and the oocyte) gap junctions. Gap junctions are composed of proteins called connexins (Figure 1-4). The connexin proteins that form the gap junctions within ovarian follicles are connexin 43 (Cx43) and 37 (Cx37). In the COC, the $\mathrm{Cx} 43$ protein is translated in gap junctions that couple the cumulus cells while $\mathrm{C} \times 37$ protein is translated exclusively in the gap junctions that couple the oocyte to the cumulus cells (Mayerhofer and Garfield, 1995; Veitch et al., 2004).

Studies in Gja4 (the gene encoding the Cx37 protein) knockout mice indicate that the presence of heterologous gap junctions are essential for folliculogenesis as the ovaries of these mice contained few or no late pre-antral or antral follicles. Thus the $\mathrm{Gja}^{-1 /}$ mice were sterile with smaller oocytes when compared to that in wild-type mice (Simon et al., 1997; Carabatsos et al., 2000). In addition, the oocytes from these follicles were less meiotically-competent when compared to follicles from control mice. These results suggest that oocyte growth and granulosa cell proliferation is dependent upon gap junction activity. 
Likewise, studies in Gja1 (the gene encoding the Cx43 protein) knockout mice have indicated a pivotal role for this protein in the maintenance of follicular development. These $\mathrm{Gja1}^{-/}$mice had fewer germ cells than wild-type mice, but as Gja1 ${ }^{-/}$mice die soon after birth, an organ culture technique was used to assess post-natal folliculogenesis. These studies revealed that there were no observable secondary follicles in the ovaries and confirmed the role of $\mathrm{Cx} 43$ in folliculogenesis (Juneja et al., 1999; Ackert et al., 2001). These results suggest that oocyte growth/hypertrophy is gap junction dependent (Juneja et al., 1999).

In the in vivo situation, the extensive metabolic and developmental coupling of the oocyte and somatic cells is essential for the maintenance of meiotic arrest in antral follicles that have not been exposed to a pre-ovulatory LH surge (Eppig et al., 2002; Zhang and Xia, 2011). Early evidence indicated that the cessation of gap junction communication occurs coincidently with GVBD (Eppig and Downs, 1987). However, there is evidence that the disruption of gap junction communication precedes GVBD. It is now understood that the onset of GVBD occurs once the level of gap junctional communication drops below a certain level. For example in the bovine COCs, GVBD is initiated once gap junction activity declines to $40 \%$ of the original level of communication, as measured by a gap junction assay (Thomas et al., 2004). In the in vitro situation, pharmacological disruption of gap junctions using the blocking agent carbonexolone resulted in resumption of meiosis in oocytes of treated follicles (Sela-Abramovich et al., 2006). 


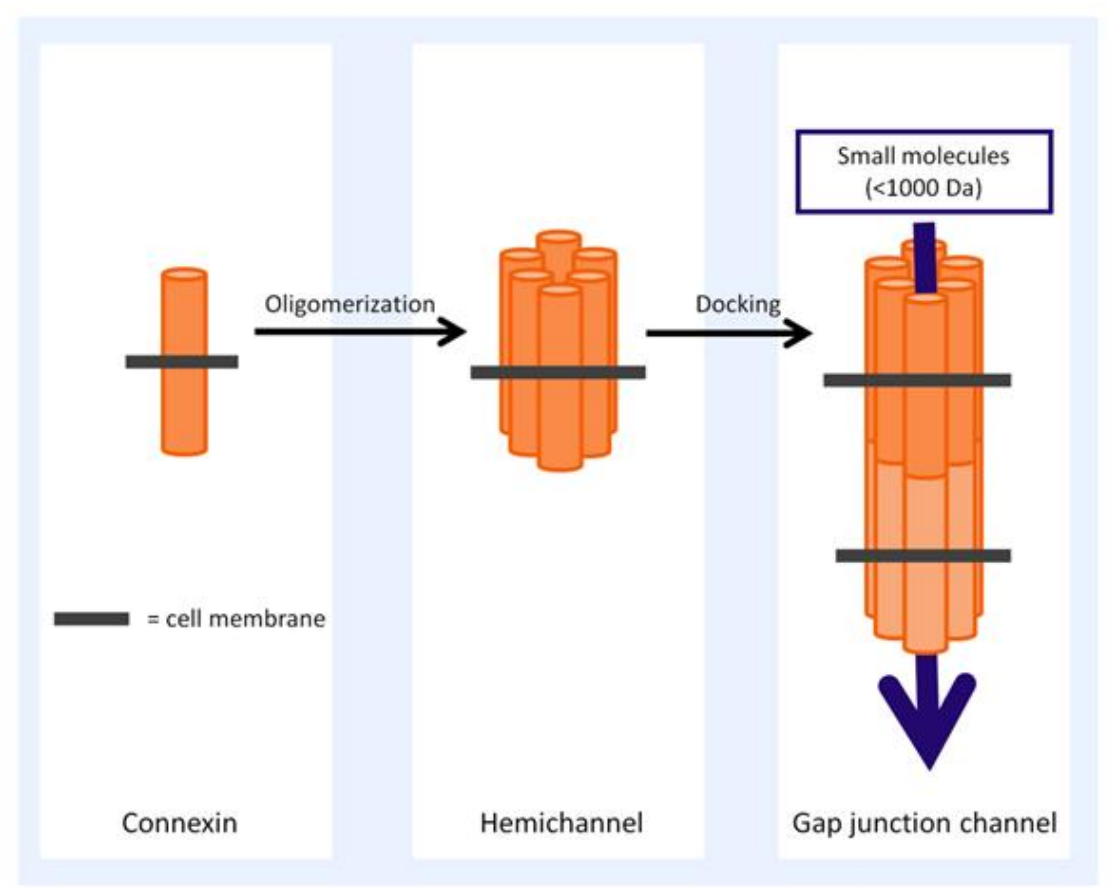

Figure 1-4: The formation and structure of gap junctions. Gap junctions can be composed of one or more different connexin proteins. In the COC, the connexins involved in the formation of gap junctions are Cx37 and Cx43. Hemichannels or connexons are made up of 6 connexin proteins. Each of the cells contributes one hemichannel and once connected to a hemichannel in the adjacent cell forms a gap junction. This figure is from Campen (2013), with permission.

\subsection{Cyclic Nucleotides and Phosphodiesterases in the Follicle}

The accepted dogma is that meiotic arrest is directly maintained by high concentrations of cAMP within the oocyte (Mehlmann et al., 2002). The mechanism of action involves high cAMP levels that activate protein kinase A (PKA) and result in the subsequent phosphorylation and suppression of maturation-promoting factor (MPF) activity, thus preventing re-entry into the cell cycle (Mehlmann, 2005a; Vaccari et al., 2008).

\subsubsection{Cyclic AMP}

Experimental manipulation to increase cAMP levels in oocytes cultured in vitro using pharmacological agents that either stimulate cAMP levels or prevent CAMP hydrolysis have been shown to prolong meiotic arrest. For example, two commonlyused cAMP analogues dibutryl cAMP (dbcAMP) and 8-bromoadenosine cyclic monophosphate (8-bromo cAMP) have both been shown to prolong meiotic arrest in mouse and bovine oocytes in vitro (Cho et al., 1974; Aktas et al., 2003).

Furthermore, the use of phosphodiesterase (PDE) inhibitors to suppress the hydrolysis of CAMP has also proved to be effective in maintaining meiotic arrest. For 
example, the broad spectrum PDE inhibitor (IBMX) as well as PDE3A-specific inhibitors (milrinone and cilostamide) have been shown to increase cAMP levels within the oocyte and prolong the duration of meiotic arrest in cultured bovine and rat oocytes (Tsafriri et al., 1996; Thomas et al., 2002).

It is hypothesised that the cAMP present in mammalian oocytes is synthesised by the oocyte itself and/or by the cumulus cells. The predominance of either oocytederived or cumulus cell-derived intra-oocyte cAMP may be species-specific. In the first instance, varying amounts of cAMP can be produced in the oocyte itself in some species by the constitutive activity of a G-protein coupled receptor which activates an adenylyl cyclase. In the second instance, cAMP is produced in the cumulus and granulosa cell compartments of the follicle and is supplied to the oocyte through gap junctions (Mehlmann et al., 2002; Thomas et al., 2004; Gilchrist, 2011).

The majority of studies that have investigated the origins of CAMP have utilised specific phosphodiesterase inhibitors and have indicated that the cumulus cells are responsible for the production of the majority of the intra-oocyte cAMP (Thomas et al., 2002). A recent study using a cAMP fluorosensor has indicated that FSH stimulation results in the accumulation of CAMP in the cumulus cells and subsequently in the oocyte (Webb et al., 2002). In addition, the loss of gap junctional communication resulting in the cessation of cAMP transfer into the oocyte caused meiotic resumption in rat COCs (Sela-Abramovich et al., 2006). However, cAMP transfer from the cumulus cells into the oocyte alone is not sufficient to maintain meiotic arrest in mouse oocytes suggesting a major role of oocyte-derived cAMP in this rodent species (Vaccari et al., 2008). This indicates that the importance of somatic cell-derived cAMP and intra-oocyte cAMP concentrations in maintaining meiotic arrest is likely to be species-specific.

A number of studies supporting the importance of oocyte-derived cAMP in mice have shown that endogenous production of CAMP by adenylyl cyclases in the oocyte is sufficient to maintain meiotic arrest (Zhang and Xia, 2011). The production of cAMP by oocytes has been linked to $\mathrm{G}_{\mathrm{s}}$ activation in rodent and human models and neutralization of $\mathrm{G}_{\mathrm{s}}$ activity in mouse COCs by antibodies and RNA interference caused a decrease in cAMP levels and subsequent resumption of meiosis (Mehlmann et al., 2002; Hinckley et al., 2005; DiLuigi et al., 2008; Vaccari et al., 
2008). G-protein coupled receptor 3 (GPR3) and G-protein coupled receptor 12 (GPR12) have been identified as the predominant GPCRs in rodent oocytes responsible for maintaining cAMP levels. Studies in bovine COCs using compartment-specific (i.e. oocyte or cumulus cell) phosphodiesterase inhibitors have also suggested that in the cow, the oocyte may be able to produce adequate amounts of CAMP to maintain meiotic arrest (Thomas et al., 2002). While substantial evidence indicates that mouse oocytes are able to produce sufficient cAMP to maintain meiotic arrest, this has not been conclusively determined in other species like the rat, humans and cows.

\subsubsection{Cyclic GMP}

Cyclic GMP is produced in the somatic cells of the follicle and passes through gap junctions to the oocyte where it inhibits the hydrolysis of CAMP by PDE3A. It does this by binding to PDE3A at the same catalytic site as CAMP, but it is hydrolysed by PDE3A at a much slower rate, thus reducing the rate of CAMP hydrolysis thereby maintaining high levels of cAMP and meiotic arrest (Vaccari et al., 2009; Conti, 2011). The inhibitory effect of CGMP on PDE3A is thought to have a major role in the maintenance of meiotic arrest in ovarian follicles. Moreover, like cAMP, cGMP levels decrease at the same time as spontaneous GVBD in rat oocytes in vitro (Törnell et al., 1990). It is currently accepted that both a decrease in gap junction permeability and decreased cyclic nucleotide production results in decreased oocyte cGMP levels (Robinson et al., 2012). In agreement with this theory, increasing follicular cGMP concentrations in whole pre-ovulatory follicles using two known inhibitors of a somatic cell-derived PDE5 (a known cGMP-specific phosphodiesterase) has been shown to increase the duration of meiotic arrest of oocytes in culture (Vaccari et al., 2009). Likewise, inhibiting soluble guanylyl cyclase activity in rat COCs in vitro resulted in meiotic resumption and this effect could be ameliorated by co-treatment with a cGMP analogue (Sela-Abramovich et al., 2008)

The addition of LH to whole follicles in culture decreased cGMP levels in somatic cells in vitro, leading to subsequent decreases in the level of intra-oocyte cGMP and the resumption of meiosis (Norris et al., 2009). The action of LH on reducing cGMP levels has recently been reported to be facilitated by the down-regulation of NPR2 (the major guanylyl cyclase linked receptor in rodent ovarian follicles) as opposed to phosphodiesterase-mediated cGMP hydrolysis (Vaccari et al., 2009; Robinson et al., 
2012). These events are thought to reflect that which occurs in the follicle in vivo as a result of the pre-ovulatory LH surge. This reinforces the importance of cGMPmediated PDE3A inhibition as an integral regulatory factor in the maintenance of meiotic arrest and that breakdown or down-regulation of cGMP production may lead to the resumption of meiosis.

\subsubsection{Phosphodiesterases and the Regulation of Follicular Cyclic Nucleotide Levels}

In addition to synthesising cyclic nucleotides, there are mechanisms of cyclic nucleotide degradation in ovarian follicles. Within the superfamily of cyclic nucleotide phosphodiesterases (PDE) there are 11 families, all of which convert cyclic nucleotides into inactive forms. The PDE isoforms 3 and 4 are known to hydrolyse the majority of cAMP in most cell types in the body. In the rat ovary, PDE3A has been identified in the oocyte while PDE4B and PDE4D have been identified as potentially two of the predominant isoforms present in somatic cells. It is the combination of these isoforms that are thought to be responsible for the hydrolysis of CAMP in the rat COC (Tsafriri et al., 1996; Richard et al., 2001; Francis et al., 2011). Using in situ hybridisation, PDE4D was shown to be specifically localised to the mural granulosa cells in rats and this signal increased as the maturational stage of follicles increased, whilst PDE4B was localised to the thecal and interstitial cells (Tsafriri et al., 1996).

In rat oocytes, PDE3A activity was evident prior to spontaneous and gonadotropininduced oocyte maturation indicating that PDE3A activity is tightly regulated by the influence of inhibitory factors or stimuli (Richard et al., 2001). Additionally, the study of $P d e 3 a^{-/}$mice has been instrumental in understanding the action of PDE3A and its importance in maintaining meiotic arrest in mammalian oocytes. The Pde $3 a^{-/}$mice were infertile and oocytes from these mice were meiotically incompetent as CAMP levels remained high even after the LH surge, thus preventing meiotic resumption (Shen et al., 2010). Interestingly the loss of an upstream receptor, GPR3, which is critical for cAMP signal transduction in oocytes (Gpr3 ${ }^{-/}$oocytes) ameliorated the overwhelming effect of the loss of PDE3A activity allowing CAMP levels to decrease to levels that permitted re-entry into meiosis (Vaccari et al., 2008). While these models demonstrate the importance of PDE3A, regulation of PDE3A activity within 
the follicle is still poorly understood. Whilst PDE3A activity has been reported to be suppressed by high cGMP levels (Vaccari et al., 2009), there is some evidence that it is also regulated by phosphorylation (Francis et al., 2011).

Additionally, isoforms of PDE4 in the follicle have been shown to be regulated by LH and $\mathrm{FSH}$ and thus are thought to be physiologically relevant to the regulation of meiotic arrest (Park et al., 2003). Knockout mice have also proven informative for understanding PDE4D function in the follicle. Pde $4 d^{-/}$mice displayed impaired fertility with an inability to complete the latter stages of follicular maturation (Park et al., 2003; Conti, 2011). As discussed previously, regulation of cyclic nucleotide levels through both production and breakdown of cyclic nucleotides is used as a sensor in many systems in the body. The PDE4 family is often a target for the regulation of cAMP as it is known to be regulated by phosphorylation and changes in mRNA levels (Park et al., 2003).

Similar to CAMP, specific mechanisms of cGMP degradation exist and can be manipulated to gain a better understanding of the importance of cGMP levels on meiotic arrest. For example, an injection of the catalytic domain of a cGMP-specific phosphodiesterase (PDE9A) resulted in the resumption of meiosis in follicularenclosed mouse oocytes (Norris et al., 2009). This would also indicate that the maintenance of high cGMP levels is also a requirement for the maintenance of meiotic arrest.

\subsection{Follicular-secreted Factors involved in the Maintenance of Meiotic Arrest in vitro}

The regulation of meiotic arrest is complex and in some species that have been studied, increasing intra-oocyte cAMP levels in isolation is not sufficient to maintain meiotic arrest in oocytes. This is the case in bovine oocytes, where meiotic resumption could only prevented by co-culture with 8-bromo cAMP and granulosa cells (Aktas et al., 2003). Furthermore, this study also found that culture of COCs with the somatic cells from the follicle increased developmental competence. As such, since the initial observation suggesting that the somatic cells, in particular the granulosa cells, of the follicle produce a meiosis-inhibiting substance (Pincus and Enzmann, 1935), a number of potential candidates have been identified. These include hypoxanthine (Eppig et al., 1985), the oocyte maturation inhibitor (Tsafriri 
and Channing, 1975), nitric oxide (Nakamura et al., 2002) and more recently, C-type natriuretic peptide (Zhang et al., 2010). The commonality between all of these factors is that they all directly and indirectly have the ability to modulate intra-follicular cGMP pathways.

\subsubsection{C-Type Natriuretic Peptide (CNP) and Natriuretic Peptide Receptor 2 (NPR2)}

The natriuretic peptide family of proteins, which includes atrial natriuretic peptide (ANP) and brain natriuretic peptide (BNP), consists of small peptides containing a characteristic 17-member ring structure (Sellitti et al., 2011). There are lower circulating levels of CNP indicating that CNP acts in a paracrine manner as opposed to ANP and BNP which have much higher circulating levels and are known to have endocrine functions, namely in maintaining fluid homeostasis. CNP is linked to a number of unique functions such as endochondral ossification, nervous system function, development and health of the cardiovascular system through the regulation of smooth muscle and endothelial function as well as reproductive functions (Gutkowska et al., 1999; Sellitti et al., 2011; Kiyosu et al., 2012; Sato et al., 2012). In female mice and pigs, CNP is involved in the maintenance of meiotic arrest (Zhang et al., 2010; Hiradate et al., 2013) and there is growing evidence that it is also involved in transduction of gonadotropin signalling involved in the transition from primary to pre-antral secondary follicles (Robinson et al., 2012; Sato et al., 2012).

NPR2 (also known as NPR-B or guanylyl cyclase-B) is the high affinity receptor for CNP (Kiyosu et al., 2012), while ANP and BNP both act on natriuretic peptide receptor 1/guanylyl cyclase A (NPR1/NPR-A/GC-A) (Koller et al., 1991). The NPR2 protein is made up of an extracellular ligand-binding domain and an intracellular homology domain which contains dimerization and catalytic domains (Abbey-Hosch et al., 2005). Transcriptome analysis of mouse cumulus cells showed a high level of expression of Npr2 (Zhang et al., 2010).

The granulosa cells produce CNP which is released into the follicular fluid of the antrum and can subsequently bind to and activate NPR2 expressed on cumulus cells (and to a lesser extent, on the granulosa cells) (Zhang et al., 2010). Activation of NPR2 by CNP stimulates guanylyl cyclase activity resulting in the production of cGMP. Oocytes do not produce the requisite levels of cGMP, thus activation of 
NPR2 is involved in the maintenance of meiotic arrest as a result the production and subsequent trafficking of cGMP through gap junctions into the oocyte (Zhang et al., 2011).

Interestingly, expression levels of Npr2 mRNA are up-regulated by OSFs like BMP15, GDF9 and fibroblast growth factor 8B (FGF8B) as well as steroid hormones, namely oestradiol and testosterone (Zhang et al., 2010, 2011). It is unclear whether OSFs are able to promote sufficient Npr2 expression to maintain meiotic arrest but OSFs have been implicated in increasing oestradiol production in granulosa cells and this could contribute to the maintenance of meiotic arrest (Vanderhyden et al., 1993; Brankin et al., 2003; Lucidi et al., 2003). Furthermore, Nppc (the gene encoding CNP) and Npr2 mRNA expression are modulated during the oestrous cycle and indicate a role for CNP/NPR2 signalling in female fertility in the rat (Jankowski et al., 1997; Gutkowska et al., 1999). Treatment of mouse ovaries with LH (mimicking the pre-ovulatory LH surge) decreased the expression of Nppc mRNA in the granulosa cells. Similarly, measurement of CNP protein concentrations in human follicular fluid showed that pre-treatment with hCG resulted in a reduction in secretion of CNP (Kawamura et al., 2011). Accordingly, this suggests that CNP is involved in the maintenance of meiotic arrest in vivo and that stimulation with LH (or $\mathrm{hCG}$ ) results in a decrease in CNP and subsequently a decrease in cGMP (Tsuji et al., 2012).

Furthermore, administration of CNP to mouse and pig COCs cultured in vitro reduced the proportion of oocytes undergoing spontaneous GVBD in a dosedependent manner (Zhang et al., 2010; Kawamura et al., 2011; Hiradate et al., 2013). There is strong evidence from mouse models with mutations in Nppc and Npr2 that CNP/NPR2 signalling is required for the maintenance of meiotic arrest (Kiyosu et al., 2012; Geister et al., 2013). Thus CNP and its receptor NPR2 are involved in the maintenance of meiotic arrest through increased production of cGMP and indirect modulation of intra-oocyte cAMP concentrations.

\subsubsection{The Role of Steroid Hormones in CNP/NPR2 Signalling} Androgens, oestrogens and progestins are synthesised by the developing follicle at various stages of development. The synthesis and levels of each of these steroid hormones is dependent on the stage of follicular development and external signals 
received, including gonadotropin signalling. Follicular fluid contains high steroid hormone concentrations with particularly high concentrations of testosterone and comparatively lower concentrations of progesterone and oestradiol (Goff and Henderson, 1979; McNatty et al., 1986; Westergaard et al., 1986; Kaji et al., 1987).

Progestins have been shown to be important for the process of folliculogenesis and in particular, the process of ovulation. Progesterone receptor null mice are infertile, due to the inability to ovulate under normal gonadotropin stimulation or gonadotropin hyper-stimulation (Lydon et al., 1995). Immunohistochemical studies have localised progesterone receptors to the theca of small antral follicles and the granulosa cells of pre-ovulatory follicles following hCG stimulation in both the rat and monkey (HildPetito et al., 1988; Park and Mayo, 1991).

The role of androgens in follicular development is still not fully understood. The androgen receptor has been shown to be most highly expressed in small pre-antral and early antral follicles and it is possible that it has an essential role in the early stages of follicular development (Pelletier et al., 2000). Conversely, it has also been postulated that the most important role for androgens is as a substrate for P450 aromatase in order to produce oestradiol (Drummond, 2006).

Oestradiol is produced by the granulosa cells of the ovary (Yang and Fortune, 2008; Zhang et al., 2011). It has a range of functions in female mammals including, regulation of the oestrous cycle, sexual differentiation and a central role in follicular development. Oestradiol is first produced in appreciative amounts in follicles during the latter stages of follicular development and it is in pre-ovulatory follicles that oestradiol production is at its highest due to the large number of granulosa cells. Oestradiol has been shown to induce expression of $\mathrm{FSH}, \mathrm{LH}$ and prolactin receptors. Additionally, oestradiol has been shown to modulate cAMP signalling and this effect is regulated by the gonadotropins (Richards and Rolfes, 1980).

Initial experimental evidence suggested that testosterone and progesterone were more potent than oestradiol at inhibiting GVBD when administered in combination with dbcAMP (Kaji et al., 1987). However, the inhibitory effects of progesterone and testosterone may, at least in part, be attributed to their action as substrates for oestradiol production as it has been reported that granulosa cells aromatise testosterone to oestradiol when stimulated by cAMP (Vanderhyden et al., 1993). 
The potential role of oestradiol in regulating cumulus cell functions is further supported by reports of increased Npr2 expression in cumulus cells of mouse COCs cultured with exogenous oestradiol in vitro (Zhang et al., 2011) and of impaired cumulus cell expansion in Esr2 (oestrogen receptor $\beta$ )-deficient mice (Couse et al., 2005). Together these results imply that oestradiol is another major follicular factor that may regulate the maintenance of meiotic arrest through modulation of NPR2 expression levels and subsequent cGMP concentrations.

\subsubsection{The Role of CNP/NPR2 Signalling in the Maintenance of Meiotic Arrest in Mice}

The majority of work investigating the effects of the CNP/NPR2 regulatory pathway on the maintenance of meiotic arrest has been undertaken in mice (Zhang et al., 2010, 2011). This work has culminated in the development of a hypothetical model that illustrates the mechanism of action through which CNP may regulate meiotic arrest and how this pathway may be further modulated by oestradiol (Figure 1-5).

\subsection{Species Differences in the Regulation of Meiotic Arrest}

Mice and rats are the commonly used model organisms for research involving female reproduction in mammals. Whilst this literature review has presented a hypothetical model for the regulation of meiotic arrest in mice, it is important to note that recent evidence reveals significant discrepancies in the regulation of meiotic arrest between these two rodent species.

The first such discrepancy is that there is extensive evidence that mouse oocytes have the ability to produce sufficient cAMP to maintain meiotic arrest from localised adenylyl cyclases in the oocyte membrane (Hinckley et al., 2005; Mehlmann, 2005b). While oocyte-derived adenylyl cyclases have been identified in the rat, the ability to produce sufficient CAMP to maintain meiotic arrest has not been fully substantiated. Furthermore, modulation of CAMP levels using CAMP analogues and PDE inhibitors was shown to maintain meiotic arrest in rat oocytes but this approach was much less effective when compared to mouse oocyte (Downs, 2011). Additionally, in contrast to the mouse, administration of a cGMP analogue (8-Br-cGMP) to cultured rat COCs did not result in the maintenance of meiotic arrest (Downs, 2011). 


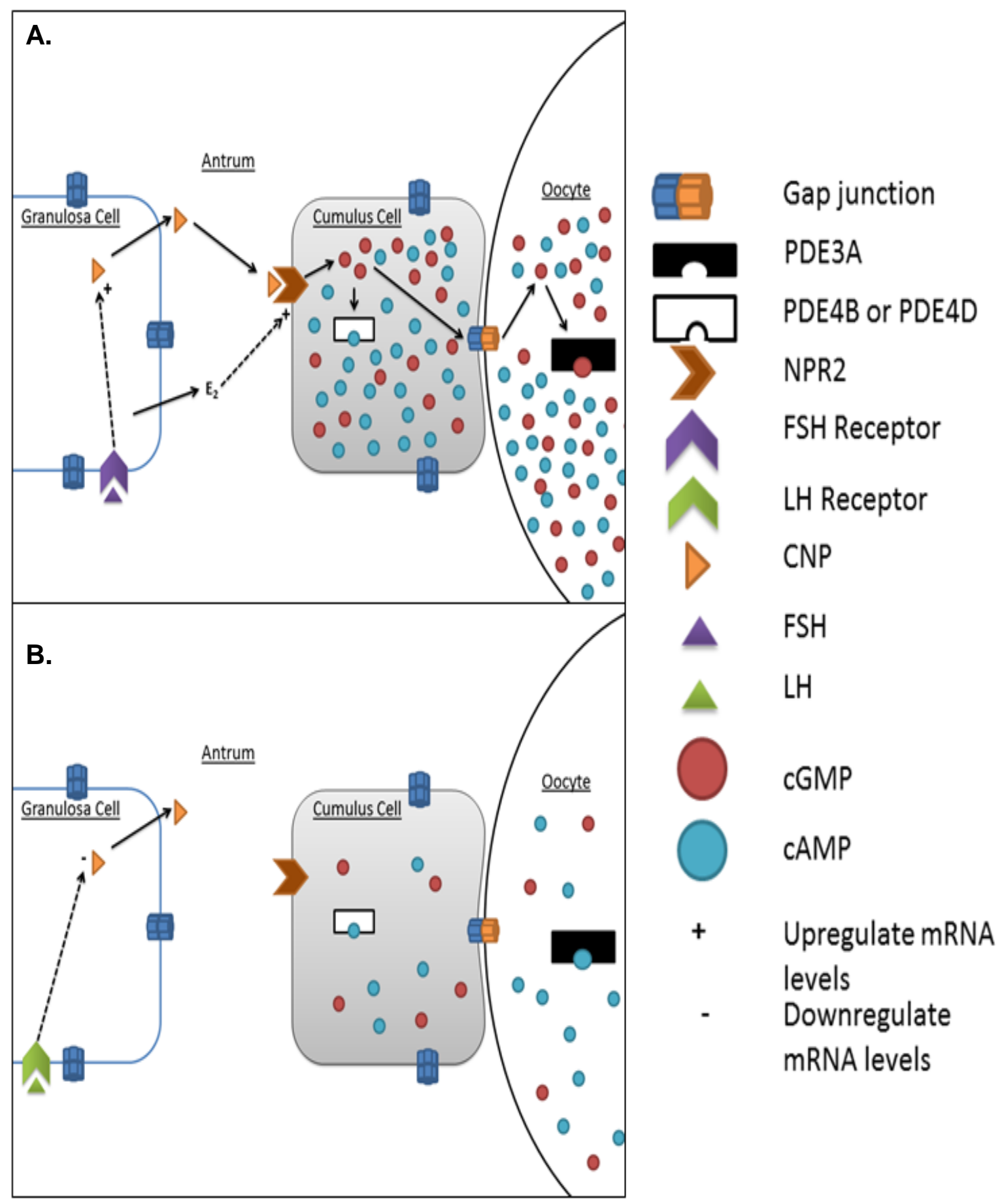

Figure 1-5: The hypothesised regulatory mechanism for meiotic arrest in the mouse. Panel A illustrates the action of CNP on its cognate receptor NPR2, which results in increased cGMP production and subsequently cGMP levels in the cumulus cells. The cGMP is transferred via gap junctions from the cumulus cells into the oocyte where it reduces the rate of CAMP hydrolysis by PDE3A. This results in high levels of CAMP and thus, maintains meiotic arrest in the oocyte. Oestradiol produced by the granulosa cells upregulates Npr2 expression in the cumulus cells, further propagating the effects of CNP described above. Furthermore, FSH has been shown to increase Nppc expression in the granulosa cells resulting in an increase in CNP synthesis. Panel B indicates that LH has been shown to decrease Nppc expression resulting in a decrease in CNP synthesis. In addition, decreased activation of NPR2 (through reduced CNP levels) decreases cGMP levels in the cumulus cells. This results in increased PDE3A hydrolysis of CAMP and lowered levels of cAMP in the oocyte culminating in the resumption on meiosis. 
Despite these significant species-specific differences, there is evidence that the hypothesised mechanism may also be relevant in rats. Both of the genes encoding for CNP and NPR2 (Nppc and Npr2, respectively) are highly expressed in the rat ovary and their expression levels are influenced by the stage of the oestrous cycle (Jankowski et al., 1997; Gutkowska et al., 1999; Noubani et al., 2000). This would indicate that a unique regulatory mechanism involving the CNP pathway may exist in rats in regards to the maintenance of high intra-oocyte cAMP levels and subsequently maintenance of meiotic arrest.

\subsection{The Overall Objectives and Aims}

The overall objective of this study was to test the validity of the hypothesised model illustrated in Figure 1-5 in maintaining meiotic arrest in rat oocytes. The effects of CNP and oestradiol alone or in combination were tested on rat COCs that were cultured in vitro for different lengths of time. With reference to this hypothesised model, this study sought to determine the effects of these treatments on four different aspects of the model pathway following both short and long incubation periods.

The first aim of this study was to assess the effects of CNP and oestradiol on gap junction permeability within rat COCs using an optimised gap junction assay. This aim tested the feasibility of the hypothesised model in terms of whether the rate of transfer of cAMP and cGMP from the cumulus cells to the oocyte via gap junctions could be modulated by these treatments.

The second aim was to measure the effects of CNP and oestradiol on cGMP levels within rat COCs. These experiments were designed to confirm previous reports that these treatments increased cGMP levels within mouse COCs (Zhang et al., 2010, 2011).

The third aim was to assess the effects of CNP and oestradiol on mRNA expression levels of key cumulus cell-derived genes involved in the hypothesised pathway. The key candidate genes were Npr2, Pde $4 b$ and Pde4d. This aim sought to elucidate the validity of previous observations that oestradiol modulates Npr2 expression levels in the mouse and rat (Noubani et al., 2000; Zhang et al., 2011) as well as address the lack of knowledge on the predominant forms of phosphodiesterases within rat cumulus cells. 
The fourth aim was to assess the effects of CNP and oestradiol on the duration of meiotic arrest in rat COCs that were cultured in vitro by assessing the timing of initiation of GVBD in treated and control COCs. This aim sought to verify the action of these potential regulatory agents on the maintenance of meiotic arrest in rat COCs using the optimised culture conditions described in this study. 


\section{Chapter 2: $\quad$ Materials and Methods}

\subsection{Chemicals, Stock Solutions and Media}

The dissection media was comprised of Leibovitz L-15 (Cat. No. 11415-064, Life Technologies, Carlsbad, California, USA) supplemented with $0.1 \%$ BSA, $100 \mathrm{IU} / \mathrm{mL}$ Penstrep (10,000 units penicillin and 10,000 $\mu \mathrm{g}$ streptomycin) (Cat. No. 151140122, Life Technologies) and $15 \mathrm{mM}$ Hepes buffer (Cat. No. H4034, Sigma-Aldrich, Auckland, NZ).

The wash media was comprised of phenol-red free M199 (Cat. No. 11043-02, Life Technologies) supplemented with $0.1 \%$ BSA and $100 \mathrm{IU} / \mathrm{mL}$ Penstrep.

The incubation media was comprised of phenol-red free M199 supplemented with $0.3 \mathrm{mg} / \mathrm{mL}$ polyvinyl alcohol (PVA; Cat No. P8136, Sigma-Aldrich).

Stock solutions of $10 \mathrm{mM}$ dipyradimole and $10 \mathrm{mM}$ rolipram (Cat. No. D9766 and R6520, respectively, Sigma-Aldrich) were made up in dimethyl sulfoxide (DMSO; Cat. No. 41639, Sigma-Aldrich). These solutions were then mixed at a 1:1 ratio and stored at $-20{ }^{\circ} \mathrm{C}$. Unless otherwise indicated, a phosphodiesterase inhibitor solution containing $5 \mathrm{mM}$ dipyradimole and $5 \mathrm{mM}$ rolipram was supplemented to all media to reach a final concentration of $50 \mu \mathrm{M}$ for both dipyradimole and rolipram.

C-Type Natriuretic Peptide (CNP; Cat. No. N8768, Sigma-Aldrich) was resuspended in $\mathrm{dH}_{2} \mathrm{O}$ to produce a $5 \mu \mathrm{M}$ stock solution. This solution was aliquoted and stored at $-20{ }^{\circ} \mathrm{C}$.

The steroid hormones used in this study were oestradiol $\left(\mathrm{E}_{2}\right.$; Cat. No. E8875, SigmaAldrich) and progesterone ( $\mathrm{P}_{4}$; Cat. No. P0130, Sigma-Aldrich). Both steroid hormones were dissolved in absolute ethanol (Cat. No. ET0016, Scharlau Chemie, Australia) to a stock solution concentration of $5 \mathrm{mg} / \mathrm{mL}$.

Calcein acetoxymethyl (AM) vials (Cat. No. C3100MP, Life Technologies) were reconstituted with DMSO to result in a $1 \mathrm{mM}$ stock solution. Aliquots of the calcein-AM stock solution were stored at $-20^{\circ} \mathrm{C}$, and were discarded if not used within one month of reconstitution. Calcein is a green fluorescent indicator with an 
excitation wavelength of $495 \mathrm{~nm}$ and an emission wavelength of $515 \mathrm{~nm}$ (Life Technologies, 2010).

The fixative used in the orcein staining experiments was comprised of 3:1 ethanol to acetic acid.

The orcein stain solution was made by dissolving $0.5 \mathrm{~g}$ of orcein powder (Cat. No. 75410, Sigma-Aldrich) in $22.5 \mathrm{~mL}$ of $\mathrm{dH}_{2} \mathrm{O}$ while heating and stirring gently for one hour. Following this, a further $27.5 \mathrm{~mL}$ of $\mathrm{dH}_{2} \mathrm{O}$ was added to result in a final concentration of $1 \% \mathrm{w} / \mathrm{v}$ orcein and the stain was filtered twice using a Whatman No.1 filter.

The de-staining solution used in the orcein staining experiments was comprised of 3:1:1 of ethanol: acetic acid: glycerol (Cat. No. G5516, Sigma-Aldrich).

\subsection{Animals and Tissue Collection}

The animals sourced for this study were excess to the requirements of breeding programmes undertaken in the School of Psychology and the School of Biological Sciences at Victoria University of Wellington (VUW). While ethical approval was not required for this study, the number of animals used was recorded and provided to the VUW Animal Ethics Committee for annual reporting purposes. Sexually immature (21-25 day old) female Sprague-Dawley rats were euthanized by carbon dioxide $\left(\mathrm{CO}_{2}\right)$ asphyxiation and the ovaries were dissected into dissection media. Each ovary was kept in a water-bath at $37^{\circ} \mathrm{C}$ until dissected.

The ovaries were transferred to a petri dish containing dissection media and trimmed of excess fat under a Leica M80 dissecting microscope (Wetzlar, Germany). The ovaries were then transferred to a new petri dish containing fresh dissection media and each visible follicle was punctured with a 20-gauge needle to liberate the COC from the follicle. The COCs were then transferred to another petri dish containing dissection media. This pool of COCs was then used to select 'healthy' COCs (i.e. COCs with two or more intact layers of cumulus cells surrounding an oocyte) for use in subsequent experiments. 


\subsection{Experimental Design}

This study was designed to investigate the effects of CNP and oestradiol alone or in combination on COCs in regards to (i) gap junction activity between the cumulus cells and the oocyte, (ii) cGMP concentrations in COCs, (iii) gene expression levels of key genes involved in intracellular cGMP signalling (Npr2, Pde4b, Pde4d) and, (iv) the proportions of oocytes that undergo GVBD. To mitigate the spontaneous resumption of meiosis that occurs upon extraction of the $\mathrm{COC}$ from the ovarian follicle, the majority of these in vitro experiments were performed under maintenance of meiotic arrest (i.e. with addition of the phosphodiesterase inhibitors dipyradimole and rolipram). Several experiments were undertaken to optimise the in vitro conditions required for this study. Thereafter, experiments were performed using a general treatment protocol that was modified to accommodate the different experimental aims.

For each replicate experiment, a range of 15 to 20 COCs were selected from the 'healthy' $\mathrm{COC}$ pool for each treatment group at each time point. The general treatment protocol involved these COCs being transferred through two wash steps in wash media before being transferred to wells of a 48-well plate containing incubation media supplemented with the relevant treatments. The duration of incubation was dependent upon the experiment and will be discussed in subsequent sections. Upon completion of the incubation period, individual oocytes were stripped of their cumulus cells. Oocytes were either processed for gap junction activity by measurement of fluorescence and/or GVBD assessment and cumulus cells were processed for qPCR. In regards to the experiments in which cGMP levels were directly measured, whole COCs were used.

\subsection{Gap Junction Assay}

The gap junction assay utilised an acetoxymethyl derivative of calcein (calcein-AM) as a fluorescent dye marker of substrate movement from cumulus cells into the oocyte. Calcein-AM is colourless and non-fluorescent due to the addition of the AM ester group which results in an uncharged molecule that can permeate cell membranes. Calcein-AM was added to the wells containing the COCs following their incubations in appropriate treatments for the appropriate predetermined incubation time. In the context of the gap junction assay, calcein-AM enters the cumulus cells 
and once intracellularly-located, is hydrolysed resulting in the production of calcein. A further one hour incubation time of the treated COCs allowed for the transfer of the fluorescent dye from the cumulus cells into the oocyte via gap junctions. Following the stripping of cumulus cells from the oocyte, the fluorescence level in the individual denuded oocytes was an indirect measure of gap junction communication within the COCs. The gap junction assay protocol that was used in this study had previously been optimised and validated for use in the rat (Campen, 2013).

The COCs used in the gap junction assays were collected as described in Section 2.2 and 2.3. All incubations were carried out at $37^{\circ} \mathrm{C}$ with $5 \% \mathrm{CO}_{2}$ and $96 \%$ humidity. For the optimisation experiment, the COCs were incubated in incubation media supplemented with either phosphodiesterase inhibitors or DMSO (control) for either 0,4 or 18 hours. In the subsequent gap junction assay experiments, all media was supplemented with phosphodiesterase inhibitors and incubation media was further supplemented with either ethanol (control), CNP (100 nM), oestradiol (200 ng/mL), CNP (100 nM) and oestradiol $(200 \mathrm{ng} / \mathrm{mL})$ in combination, or CNP $(100 \mathrm{nM})$ and progesterone $(200 \mathrm{ng} / \mathrm{mL})$ in combination for 0,4 or 18 hours. At the completion of the incubation period, all COCs were then transferred into incubation media supplemented with the appropriate treatments as described above and calcein-AM (at a final concentration of $2 \mu \mathrm{M}$ ) and incubated for a further 10 minutes. The COCs were then transferred to the final one hour incubation in incubation media supplemented with the appropriate treatments. As a result, COCs were incubated with the treatments for a total of approximately 1,5 or 19 hours.

At the end of the final incubation, the COCs were transferred to a 96-well plate (Thermo Fisher Scientific, Auckland, NZ) where single COCs were transferred through two washes in phosphate buffered saline (PBS; Cat. No. P4417. SigmaAldrich) and then into a well containing $10 \mu \mathrm{L}$ of PBS. The cumulus cells were stripped of the oocytes by vigorous pipetting to result in a denuded oocyte (DO) and a number of cumulus cells. The DOs were then transferred to a separate 96 -well plate containing PBS and the plate containing the cumulus cells was sealed and stored at $-80^{\circ} \mathrm{C}$ for qPCR analysis. The DOs were photographed to assess whether a GV was present (Figure 1-3). If no GV was observed, oocytes were noted as having initiated GVBD. The fluorescence intensity in all DOs was measured using a Leica inverted microscope (CTR4000) with a CRAIC fluorescence detection system 
(Leica Microsystems; Wetzlar, Germany). The measurements were captured over 50 milliseconds in the wavelength range of 300 to $700 \mathrm{~nm}$.

\section{5. cGMP Assay}

COCs were collected as described previously and for each replicate experiment, 100 COCs were selected from the 'healthy' COC pool for each treatment group.

Phosphodiesterase inhibitors were not supplemented to any of the media in this experiment. The COCs were transferred through two wash steps in wash media before being transferred to wells of a 48-well plate containing incubation media supplemented with the relevant treatments. The treatments that were used for the cGMP assays were incubation media supplemented with ethanol (control), CNP (100 nM), oestradiol (200 ng/mL) or CNP (100 nM) and oestradiol (200 ng/mL) in combination. COCs were incubated with each of the treatments for 5 hours.

At the end of the incubation period, COCs from each of the treatment groups were pooled into a microcentrifuge tube and centrifuged for 10 minutes at $800 \times g$. The excess media was removed and $10 \mu \mathrm{L}$ of $0.1 \mathrm{M} \mathrm{HCl}$ was added to each tube and vortexed briefly. The tubes were then incubated on ice for five minutes before being stored at $-80{ }^{\circ} \mathrm{C}$ until further processing.

The measurement of cGMP concentrations within pools of 100 COCs was carried out using the reagents provided by the cGMP Direct Immunoassay Kit (Cat. No. ab65356, Abcam, Cambridge, UK) following a modification of the manufacturer's instructions. In detail, a $2 \mathrm{pmol} / \mu \mathrm{L}$ cGMP working solution was prepared for the standard curve by diluting the $10 \mathrm{pmol} / \mu \mathrm{L}$ cGMP standard stock solution in $0.1 \mathrm{M}$ $\mathrm{HCl}$. This was subsequently diluted in $0.1 \mathrm{M} \mathrm{HCl}$ to produce a standard curve incorporating $0.039,0.078,0.156,0.3125,0.625,1.25,2.5,5$ and $10 \mathrm{pmol} / 50 \mu \mathrm{L}$ standards. To $10 \mu \mathrm{L}$ of each standard or sample, an aliquot of $5 \mu \mathrm{L}$ of neutralising buffer was added to neutralize the $\mathrm{HCl}$. Thereafter, both standards and samples were acetylated with $5 \mu \mathrm{L}$ of the acetylating reagent mix, vortexed for three seconds, and the acetylation mix was evaporated by incubation at room temperature for 10 minutes. Finally, $90 \mu \mathrm{L}$ of assay buffer was added to result in a final standard/sample volume of $110 \mu \mathrm{L}$ and the tubes mixed well.

To each Protein G coated well, $50 \mu \mathrm{L}$ of each of the samples and standards were added in duplicate. Thereafter, $10 \mu \mathrm{L}$ of cGMP antibody was added per well and the 
plate was incubated for one hour at room temperature with gentle agitation. A $10 \mu \mathrm{L}$ aliquot of cGMP-HRP was added and the samples were incubated at room temperature for a further one hour with gentle agitation. The plate was washed five times with the $1 \times$ assay buffer and then $100 \mu \mathrm{L}$ of HRP developer was added to each well. The plate was incubated for a further hour at room temperature under gentle agitation. Finally, the reaction was stopped by adding $100 \mu \mathrm{L}$ of $1 \mathrm{M} \mathrm{HCl}$.

The AbCAM cGMP Direct Imunnoassay Kit has a detection range of 0.04 $10 \mathrm{pmol} / 50 \mu \mathrm{L}$ (i.e. per well). The absorbance of each of the wells at $450 \mathrm{~nm}$ was measured using a VICTOR3 multilabel plate reader (Perkin Elmer, Waltham, MA, USA). A control sample containing $100 \mathrm{COC}$ was included in each of the replicates, in order to account for variance between replicates.

\subsection{Quantitative PCR (qPCR)}

In order to optimise a TaqMan quadriplex qPCR reaction, pools of 50 COCs were used to produce template cDNA. The COCs were extracted from the ovaries as described in Section 2.2. Healthy COCs were selected and then washed twice in PBS before being collected into a microcentrifuge tube and centrifuged at $800 \times g$ for 10 minutes. Excess PBS was removed and the pellet containing intact COCs was stored at $-80{ }^{\circ} \mathrm{C}$ until subsequent RNA extraction.

The experimental samples contained only the cumulus cells that were collected from individual COCs used in the gap junction assay experiments. It is important to note that each sample contained cumulus cells from one individual COC. Briefly, the treatment groups included COCs incubated in media supplemented with either ethanol (control), CNP (100 nM), oestradiol (200 ng/mL), CNP (100 nM) and oestradiol (200 ng/mL) in combination, or CNP (100 nM) and progesterone $(200 \mathrm{ng} / \mathrm{mL})$ in combination for a total of 1,5 or 19 hours. For each of the five experimental replicates, three out of the 8-10 COCs that were exposed to each treatment regime at each time point, were randomly selected for qPCR analyses. Consequently for each treatment group at each time point, a total of $11-15$ individual cumulus cells samples were used for qPCR analyses. The CC's were stored at $-80{ }^{\circ} \mathrm{C}$ until RNA extractions were performed. 


\subsubsection{RNA Extraction}

Extraction of total RNA was performed using the ArrayPure ${ }^{\mathrm{TM}}$ Nano-scale RNA Purification Kit (Cat. No. MSPS04050, Epicentre, Madison, WI, USA) following the manufacturer's instructions. Briefly, a solution of $5 \mu \mathrm{g} / \mu \mathrm{L}$ Proteinase $\mathrm{K}$ diluted in Nano-Scale Lysis solution was prepared at a ratio of 1:30 (v/v) and then vortexed to mix. Because the samples had been collected for previous gap junction measurements, samples were stored in 96-well plates. Aliquots of $30 \mu \mathrm{L}$ of the diluted Proteinase $\mathrm{K}$ solution was added to each frozen sample, mixed thoroughly by pipetting and then the entire sample was transferred into individual clean microcentrifuge tubes.

The samples were incubated at $\sim 68^{\circ} \mathrm{C}$ for 15 minutes before being placed on ice for 3-5 minutes. At this point, $18 \mu \mathrm{L}$ of MPC protein precipitation reagent was added to each of the samples and mixed thoroughly by vortexing. Thereafter the resulting debris was pelleted by centrifugation at $13,400 \times g$ at $4{ }^{\circ} \mathrm{C}$ for 7 minutes and the supernatant was then transferred into a clean $0.5 \mathrm{~mL}$ microcentrifuge tube. A $50 \mu \mathrm{L}$ aliquot of RNase-free isopropanol (Cat. No. APPA39281000PE, Global Science, NZ) was added to the supernatant and vortexed. Subsequently, the RNA and contaminating DNA was pelleted by centrifugation at $13,400 \times g$ at $4{ }^{\circ} \mathrm{C}$ for 5 minutes which allowed for the removal of the excess isopropanol and the pellet was air-dried for a further 5 minutes. Meanwhile, RNase-Free DNase I was diluted in DNase Buffer at a dilution factor of $1: 40(\mathrm{v} / \mathrm{v})$. An aliquot of $20 \mu \mathrm{L}$ of the DNase I solution was added to each of the samples to resuspend the nucleic acid pellet. The samples were then incubated at $37^{\circ} \mathrm{C}$ for 30 minutes. At the end of the incubation period, $20 \mu \mathrm{L}$ of $2 \times$ Nano-scale Lysis solution was added to each sample and mixed well. After which, $20 \mu \mathrm{L}$ of the MPC protein precipitating reagent was added and the samples were mixed before being placed on ice for 3-5 minutes. The samples were then centrifuged at $13,400 \times g$ at $4{ }^{\circ} \mathrm{C}$ for 5 minutes to pellet the debris. The supernatant was carefully removed and transferred to a clean tube and $50 \mu \mathrm{L}$ of RNase-free isopropanol was added to precipitate the RNA and the samples were mixed by vortexing.

The purified RNA was pelleted by centrifugation at $13,400 \times g$ at $4{ }^{\circ} \mathrm{C}$ for 5 minutes and excess isopranol was removed before the pellet was rinsed with $50 \mu \mathrm{L}$ of $70 \%$ ethanol (Cat. No. APPA39281000PE, Global Science). The samples were 
centrifuged at $13,400 \times g$ at $4{ }^{\circ} \mathrm{C}$ for 3 minutes and the excess ethanol was removed. The RNA pellet was air-dried for 5 minutes and then resuspended in $10 \mu \mathrm{L}$ of ultrapure (U/P) $\mathrm{dH}_{2} \mathrm{O}$ (Cat. No. 10977, Life Technologies) by vortexing for two minutes and then briefly centrifuged. To assist the resuspension process, the RNA samples underwent a final incubation at $55-58{ }^{\circ} \mathrm{C}$ for 2 minutes before being vortexed and then stored at $-80{ }^{\circ} \mathrm{C}$.

\subsection{2. cDNA Synthesis}

Complimentary DNA (cDNA) was synthesised using the reagents supplied in the SuperScript ${ }^{\circledR}$ VILO ${ }^{\text {TM }}$ cDNA Synthesis Kit (Cat. No. 11754-050, Life Technologies) following manufacturer's instructions. A master-mix solution sufficient for 10 samples was prepared on ice that consisted of $40 \mu \mathrm{L}$ of $5 \times$ VILO $^{\text {TM }}$ Reaction Mix, $40 \mu \mathrm{L}$ of $\mathrm{U} / \mathrm{P} \mathrm{dH}_{2} \mathrm{O}$ and $20 \mu \mathrm{L}$ of $10 \times$ SuperScript ${ }^{\circledR}$ Enzyme Mix .The entire $10 \mu \mathrm{L}$ of RNA sample was added to a new tube followed by $10 \mu \mathrm{L}$ of the master-mix solution. Following a brief vortex and centrifugation step, the samples were then placed in the Rotor-Gene ${ }^{\mathrm{TM}} 6000$ Rotary 56 Analyzer (Model No. 11754-050, Corbett Life Science, Sydney, Australia) and incubated at $25{ }^{\circ} \mathrm{C}$ for 10 minutes followed by incubation at $42{ }^{\circ} \mathrm{C}$ for 120 minutes. This reaction was terminated by an incubation step at $85{ }^{\circ} \mathrm{C}$ for 5 minutes. The resultant samples of cDNA were then stored at $-20{ }^{\circ} \mathrm{C}$.

\subsection{3. $\quad$ qPCR}

This study utilised two different qPCR methodologies for the determination of relative gene expression levels. For the optimisation steps, both the SYBRß Green and TaqMan methods were used. Determination of optimal primer concentrations was undertaken using SYBR Green chemistry while probe optimisation steps were performed using TaqMan chemistry. The forward and reverse oligonucleotide primers and probes for each of the target genes were designed using the Beacon Designer software package (Premier Biosoft International, USA) and these are listed in Table 2-1.

Following successful optimisation of the qPCR protocol, the relative gene expression levels in all experimental cDNA samples were determined using an optimised TaqMan quadriplex qPCR methodology. 
Table 2-1: NCBI Accession numbers and nucleotide sequences for the TaqMan probe and forward $(F)$ and reverse (R) primers for the genes investigated in this study.

\begin{tabular}{|c|c|c|c|}
\hline Gene & $\begin{array}{l}\text { Accession } \\
\text { Number }\end{array}$ & TaqMan (Hydrolysis) Probe (5' - 3') & Primers \\
\hline Pde4b & NM_017031 & [6FAM]CAGCGAACAACACGGCGATGA[BHQ1] & $\begin{array}{l}\text { F - CAAGGAACTCCTCACTTC } \\
\text { R - GGGTGAAATTGTTTCTTACG }\end{array}$ \\
\hline Pde4d & NM_001113332 & [ROX]СCTCCTCTTCAACCTGCTCGTCA[BHQ2] & $\begin{array}{l}\mathrm{F} \text { - GACAGTGGAAGTCAAGTG } \\
\mathrm{R} \text { - GGCTTTCCTCTTCTGCTA }\end{array}$ \\
\hline Npr2 & NM_053838 & [HEX]CAATGGTCACTGTGTCTCCACTTGA[BHQ1] & $\begin{array}{l}\text { F - GCTGTTGGTACTTGGATG } \\
\text { R - CAGAGGGCTTATATGACTTC }\end{array}$ \\
\hline Rp/19 & NM_031103 & [CY5]CCAATGCCAACTCTCGTCAACAGAT[BHQ3] & $\begin{array}{l}\mathrm{F} \text { - CCCAATGAAACCAACGAAA } \\
\mathrm{R}-\text { GGGAATGGACAGTCACAG }\end{array}$ \\
\hline
\end{tabular}

\subsubsection{Primer Optimisation}

The Brilliant II SYBR® Green QPCR Master Mix kit (Cat. No. 600828, Agilent Technologies, CA, USA) used in this study utilises the SYBR® Green I fluorescent dye which binds non-specifically to double-stranded (ds) DNA. As a result, in the denaturation step of the PCR cycle, there is little fluorescence as only single stranded DNA is present. Subsequently during the annealing step, the synthesis of ds DNA allows for binding of the SYBRß Green I dye resulting in increased fluorescence and this can be monitored in a linear fashion over a range of successive PCR cycles. The threshold cycle $\left(\mathrm{C}_{\mathrm{q}}\right)$ is defined as the cycle at which the intensity of the fluorescent signal is significantly higher than the background fluorescence and is dependent on the initial concentration of the target gene in the sample (Agilent Technologies, 2009).

Table 2-2: Final optimised forward and reverse primer and TaqMan probe concentrations (nM) that were used in the quadriplex qPCR reactions.

\begin{tabular}{cccc}
\hline \multirow{2}{*}{ Gene } & \multicolumn{2}{c}{ Primer $(\mathbf{n M})$} & \multirow{2}{*}{ TaqMan Probe $(\mathbf{n M})$} \\
\cline { 2 - 3 } & Forward & Reverse & \\
\hline Pde4b & 500 & 300 & 300 \\
Pde4d & 200 & 200 & 100 \\
Npr2 & 100 & 200 & 200 \\
Rpl19 & 300 & 200 & 100 \\
\hline
\end{tabular}


The reagents and protocols from the Brilliant® II SYBR® Green QPCR Master Mix kit were used for primer optimisation. In brief, after thawing the primers and CDNA samples, a master mix was made up for each of the primer sets to be tested. In order to determine the optimal forward and reverse primer concentrations, combinations of the forward and reverse primer concentrations were titrated between the concentration of $50 \mathrm{nM}$ and $300 \mathrm{nM}$. Each gene was assessed individually and the combination of most dilute primer concentrations that resulted in the lowest $\mathrm{C}_{\mathrm{q}}$ value was chosen as the optimised primer concentration (Table 2-2). For each different primer set concentration, a master-mix solution that contained $26 \mu \mathrm{L}$ of $2 \times$ SYBR Green Master Mix, forward and reverse primers and 1.04 to $3.12 \mu \mathrm{L}$ of template cDNA was made up to $52 \mu \mathrm{L}$ with $\mathrm{U} / \mathrm{P} \mathrm{dH}_{2} \mathrm{O}$. After mixing, duplicate aliquots of $25 \mu \mathrm{L}$ of the master mix containing cDNA were pipetted into $0.1 \mu \mathrm{L}$ strip tubes. The PCR reaction was run on a Rotor-Gene ${ }^{\mathrm{TM}} 6000$ Rotary 56 Analyzer (Corbett Research) under the following thermal conditions: one cycle at $95{ }^{\circ} \mathrm{C}$ for 10 minutes, 40 cycles of $95^{\circ} \mathrm{C}$ for 15 seconds and $60{ }^{\circ} \mathrm{C}$ for 60 seconds and a final melt step which involved heating the samples from $60{ }^{\circ} \mathrm{C}$ to $95{ }^{\circ} \mathrm{C}$ at $0.5{ }^{\circ} \mathrm{C}$ increments for 5 seconds each.

\subsubsection{Probe Optimisation and qPCR Sample Analysis}

For this study, a quadriplex TaqMan reaction was utilised that involved the measurement of genes thought to be involved in the modulation of intracellular levels of cGMP within rat cumulus cells, namely, phosphodiesterase 4B (Pde4b), phosphodiesterase 4D (Pde4d) and natriuretic peptide receptor 2 (Npr2). A previously validated reference gene, 60S ribosomal protein L19 ( $R p / 19)$, was used to correct for RNA input and all results are relative to the reference gene (Crawford and McNatty, 2012; Ekart et al., 2013).

The sequence of the probes and the relevant fluorophores and quenchers that were used are listed in Table 2-1. The probes were designed such that the fluorophore (either 6FAM, ROX, HEX or Cy5) was located at the 5' end of the sequence and the quencher was located at the 3 ' end. This combination of fluorophore and quencher underpins the TaqMan chemistry. While the probe is annealed to the target sequence or unhybridised, no fluorescence is measured due to the proximity of the quencher to the fluorophore. Consequently, during the annealing-extension step, the 
fluorophore and quencher are separated as a result of the DNA polymerase action. This results a measurable increase in fluorescence.

The reagents and protocols from the Brilliant Multiplex QPCR Master Mix (Cat. No. 600553, Agilent Technologies, CA, USA) were used for probe optimisation and for analysis of experimental samples. In order to determine the optimal probe concentrations, differing probe concentrations were titrated between 50 and $300 \mathrm{nM}$. For each probe concentration, a mastermix solution containing $26 \mu \mathrm{L}$ of $2 \times$ Brilliant multiplex qPCR Master Mix, the probe, optimised forward and reverse primer concentrations, and 1.04 to $3.12 \mu \mathrm{L}$ of template cDNA was prepared to a final volume of $52 \mu \mathrm{L}$ with $\mathrm{U} / \mathrm{P} \mathrm{dH}_{2} \mathrm{O}$. Duplicate $25 \mu \mathrm{L}$ aliquots of master mix for each probe concentration were then added to strip tubes, capped and run on the Rotor$G^{\text {Gene }}{ }^{\mathrm{TM}} 6000$ Rotary 56 Analyzer. The thermal cycling program described for SYBR ${ }^{\circledR}$ Green reactions was used with the exclusion of the final melt step. Optimal probe concentrations were determined as the lowest concentration that yielded the lowest $\mathrm{C}_{q}$ value for each gene without compromising the endpoint fluorescence.

Optimised primer and probe concentrations (Table 2-2) were then used for subsequent gene expression analyses of experimental samples.

All samples were run in duplicate and corrected for the total amount of cDNA present using Rp/19 as the reference gene. As a large number of samples were to be analysed, multiple reaction runs were undertaken, thus samples were also corrected to a calibrator sample that was present in every run. Therefore, the $2^{-\Delta \Delta C T}$ method was then employed to determine the fold-change in expression of the candidate genes (Livak and Schmittgen, 2001).

\subsubsection{Multiplex Optimisation}

Prior to assessing any of the experimental samples, the reaction efficiencies for each of the genes were assessed. A serial dilution of CDNA from a pool of $50 \mathrm{COCs}$ was prepared (1:1-1:128) by diluting each of the successive dilutions in $\mathrm{U} / \mathrm{P} \mathrm{dH}_{2} \mathrm{O}$. Using the TaqMan protocol and optimised primer and probe concentrations, the amplification efficiencies were calculated as shown in Table 2-3. Due to low gene abundancy, $P d e 4 b$ expression analysis within the quadriplex reaction could not be fully optimised. 
Table 2-3: The amplication efficiency for each of the genes in the multiplex qPCR reactions.

\begin{tabular}{cc}
\hline Gene & Efficiency (\%) \\
\hline Pde4b & - \\
Pde4d & 90 \\
Npr2 & 93 \\
Rpl19 & 98 \\
\hline
\end{tabular}

\subsection{Assessment of GVBD and Orcein Staining}

The initiation of GVBD was assessed under a Leica inverted microscope by visualising the presence or absence of a GV in all COCs that were used in the gap junction assay as described in Section 2.4. As such, all of the treatment groups were the same. In detail, all media was supplemented with the phosphodiesterase inhibitors and either ethanol (control), CNP (100 nM), oestradiol $(200 \mathrm{ng} / \mathrm{mL})$, CNP (100 nM) and oestradiol $(200 \mathrm{ng} / \mathrm{mL})$ in combination, or CNP (100 nM) and progesterone $(200 \mathrm{ng} / \mathrm{mL})$ in combination, for a total of 1,5 or 19 hours.

A subsequent experiment was performed in order to better assess differences in the timing of meiotic resumption due to the exposure of $\mathrm{COC}$ to a combination of CNP and oestradiol using an orcein staining method to clearly identify meiotic stages. For each of the treatment groups, 12-15 COCs were collected and cultured as previously described (Sections 2.2 and 2.3). To enable the unrestricted resumption of meiosis in the cultured COCs, the PDE inhibitor solution was not used in these experiments. COCs were incubated in incubation media supplemented with either ethanol (control) or CNP (100 nM) and oestradiol ( $200 \mathrm{ng} / \mathrm{mL})$ in combination for 5 hours. A noincubation control was also collected and this served as a 0 hour (no treatment, no incubation time) control. The COCs were transferred through two washes in PBS. The oocytes were then denuded from the attached cumulus cells by vigorous pipetting in PBS. Denuded oocytes were then assessed for the presence or absence of the GV by observation using the Leica inverted microscope and photographed.

Following this preliminary assessment of meiotic resumption, oocytes were fixed in 3:1 ethanol:acetic acid mix for four hours. The oocytes were then placed onto slides that contained a small amount of the fixing solution. A coverslip that had petroleum jelly applied at the four corners was placed over the oocytes. Pressure was slowly 
applied to the coverslip until the oocytes were held in place but did not squash. Two opposite sides of the coverslip were then coated in clear nail varnish and once dry, the orcein stain was applied to under one side of the coverslip using a paper wick to draw the solution through. The slides were then kept in a humid box for between 75 and 90 minutes. The stain was removed by applying the de-staining solution under the coverslip in the same manner as described above. Once the last of the stain had been removed, the remaining two sides of the coverslip were sealed. The slides were observed and photographed on a fluorescent Leica microscope. After morphological examination, oocytes were assessed as either being in the diplotene stage of prophase I (i.e. contained a GV) or in a subsequent stage of meiosis.

\subsection{Statistical Analysis}

All statistical analyses were performed using the GraphPad Prism 5 software program unless stated otherwise.

For the gap junction assay, data were normalised against the mean fluorescence value for the control DOs in the 1 hour incubation group in each replicate experiment. Briefly, the mean fluorescence was calculated for the DOs in the control group that were incubated for a total of 1 hour in total. All the raw fluorescence values were then normalised by dividing the raw fluorescence values of each DO by the mean fluorescence value of the control DOs after the 1 hour incubation period. These normalised values were then checked for normality. As no transformation yielded a normal distribution, data was ranked and two-way ANOVA was performed on the ranked data. Where individual effects (either time or treatment), were found to be significant, either a Mann-Whitney test or a Kruskal-Wallis ANOVA with Dunn's post-hoc test was performed.

The data from the cGMP assay was analysed first by subtracting the absorbance of each of the samples and standards from the value of the blank ( 0 nM cGMP without the antibody). Following this, a standard curve was created by plotting the absorbance against the concentrations of the standards. Using the formula of the line of best fit for this standard curve, unknown protein concentrations were then calculated from the standard curve.

As described in Section 2.6.3.2, the $2^{-\Delta \Delta C T}$ method was used to calculate the foldchange in gene expression. This was then assessed for normality and as no 
transformation resulted in a normal distribution, data was log-transformed in order to stabilise the residual variance. For PDE4D data, it was necessary to first add 1 to each of the values before the data was log-transformed. The transformed values were then fitted to a repeated measures model using the Residual Maximum Likelihood as implemented in GenStat ( $16^{\text {th }}$ Edition) software. Where significant effects were seen for either of the main effects (either treatment or incubation length), further analysis was undertaken using a Kruskal-Wallis test with Dunn's post-hoc tests in GraphPad Prism 5 software.

All GVBD data are depicted in the figures as a proportion, that is, the number of oocytes that had undergone GVBD in relation to the total number of oocytes that had been cultured for each treatment. Chi squared tests were performed to determine if the proportion of oocytes that had initiated meiotic resumption were different. Where a significant effect was found, the effects (either time or treatment) were assessed separately using either a Chi squared test or Fisher's exact test. 


\section{Chapter 3: $\quad$ Results - Optimisation Studies}

\subsection{The Effect of Phosphodiesterase Inhibitors}

(Dipyradimole and Rolipram) on Gap Junction Communication

and the Duration of Meiotic Arrest in rat COCs Cultured in vitro

\subsubsection{The Effects of Phosphodiesterase Inhibitors on Gap}

Junction Communication in Rat COCs cultured in vitro

Incubation of rat COCs in media supplemented with phosphodiesterase inhibitors (dipyradimole and rolipram) resulted in increased $(p<0.0001)$ dye transfer from the cumulus cells to the oocyte when compared to the control COCs. Furthermore, there was a significant effect $(p<0.0001)$ of incubation time on dye transfer (Figure 3-1). Additionally, in both the control and phosphodiesterase inhibitor-treated COCs, significant decreases in fluorescent dye transfer were identified when the one and five hour incubation groups were compared to the 19 hour incubation group $(p<0.0001)$.

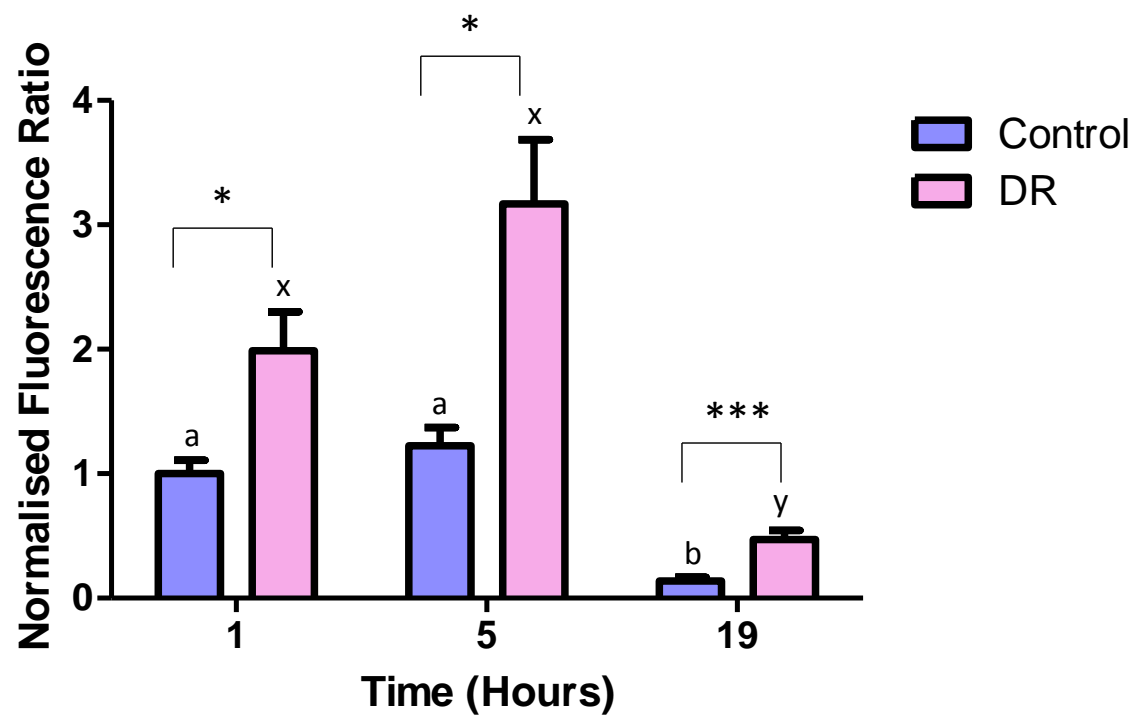

Figure 3-1: Fluorescent dye transfer measured in denuded oocytes following culture of rat COCs with or without phosphodiesterase inhibitors (DR) for 1,5 or 19 hours. All values were normalised to the mean fluorescence in controls after a 1 hour incubation. For each replicate, $10 \mathrm{COCs}$ were cultured in each treatment for each time period. Bars represent mean normalised fluorescence $\pm S E M$ of three replicates ( $N=30$ per group). Two-way ANOVA indicated a significant difference as a result of treatment $(p<0.0001)$ and incubation length $(p<0.0001)$. At each of the time points, there was a significant difference in fluorescent dye transfer as denoted by * (Mann-Whitney Test, ${ }^{*} p<0.05,{ }^{* *} p<0.01,{ }^{* * *} p<0.001$ ). Furthermore, comparisons within the control and DR-treated groups showed that there were significant differences in fluorescent dye transfer over time as denoted by consecutive letter pairs $(a \& b$ or $x \& y)$ (Kruskal-Wallis Test, $p<0.0001$ ). 


\subsubsection{The Effects of Phosphodiesterase Inhibitors on GVBD in}

Rat COCs cultured in vitro

Incubation of rat COCs in media supplemented with phosphodiesterase inhibitors (dipyradimole and rolipram) did not significantly alter GVBD rate (Figure 3-2).

Moreover, incubation time had no overall effect on the proportion of oocytes that had initiated GVBD (Figure 3-2).

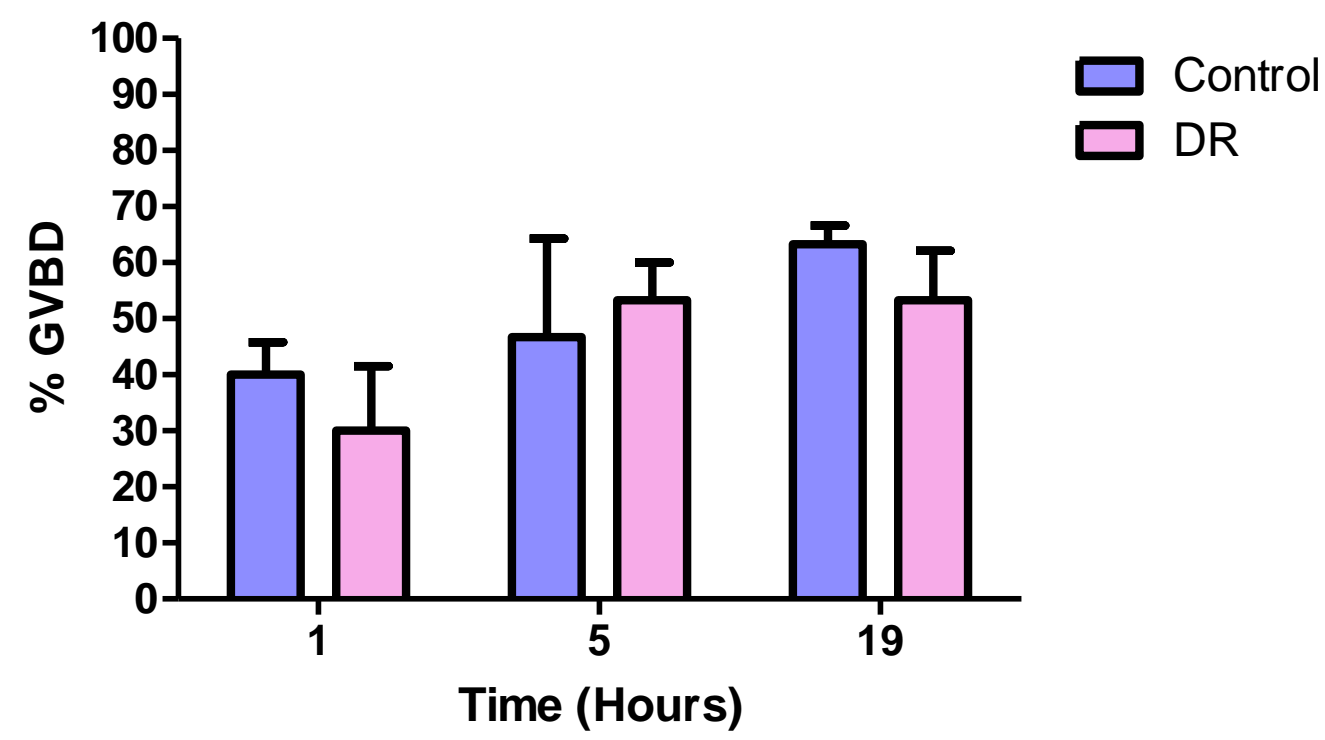

Figure 3-2: The proportion of rat oocytes that had initiated GVBD following culture in the presence (DR) or absence (control) of phosphodiesterase inhibitors for 1, 5 or 19 hours. For each replicate experiment, $10 \mathrm{COCs}$ were cultured in each treatment for each time period. Bars represent mean percentage GVBD $\pm S E M$ of three replicates ( $N=30$ per group). Chi-squared tests indicated no significant effect of any of the treatment groups at any of the time points on GVBD rate were found $(p>0.05)$. 


\subsection{The Effects of Increasing doses of C-Type Natriuretic}

\section{Peptide (CNP), Oestradiol and Progesterone on the Duration of}

\section{Meiotic Arrest in Rat COCs Cultured in vitro}

In order to determine the lowest effective dose for each treatment, a preliminary experiment was undertaken whereby a range of three doses for each of the treatments (i.e. CNP, oestradiol and progesterone) were tested for their effects on the proportions of oocytes that initiated GVBD following exposure of COCs in vitro.

\subsubsection{The Effects of Increasing Doses of CNP on GVBD in Rat COCs cultured in vitro}

A significant difference in the rate of meiotic resumption at the different incubation times was identified (Figure 3-3). While no effect of the treatments was identified $(p>0.05)$, there was an effect of incubation time in both the $10 \mathrm{nM}(\mathrm{p}=0.0060)$ and $100 \mathrm{nM}(\mathrm{p}=0.0130)$ doses of CNP after 18 hours of incubation compared to that after 4 hours of incubation.

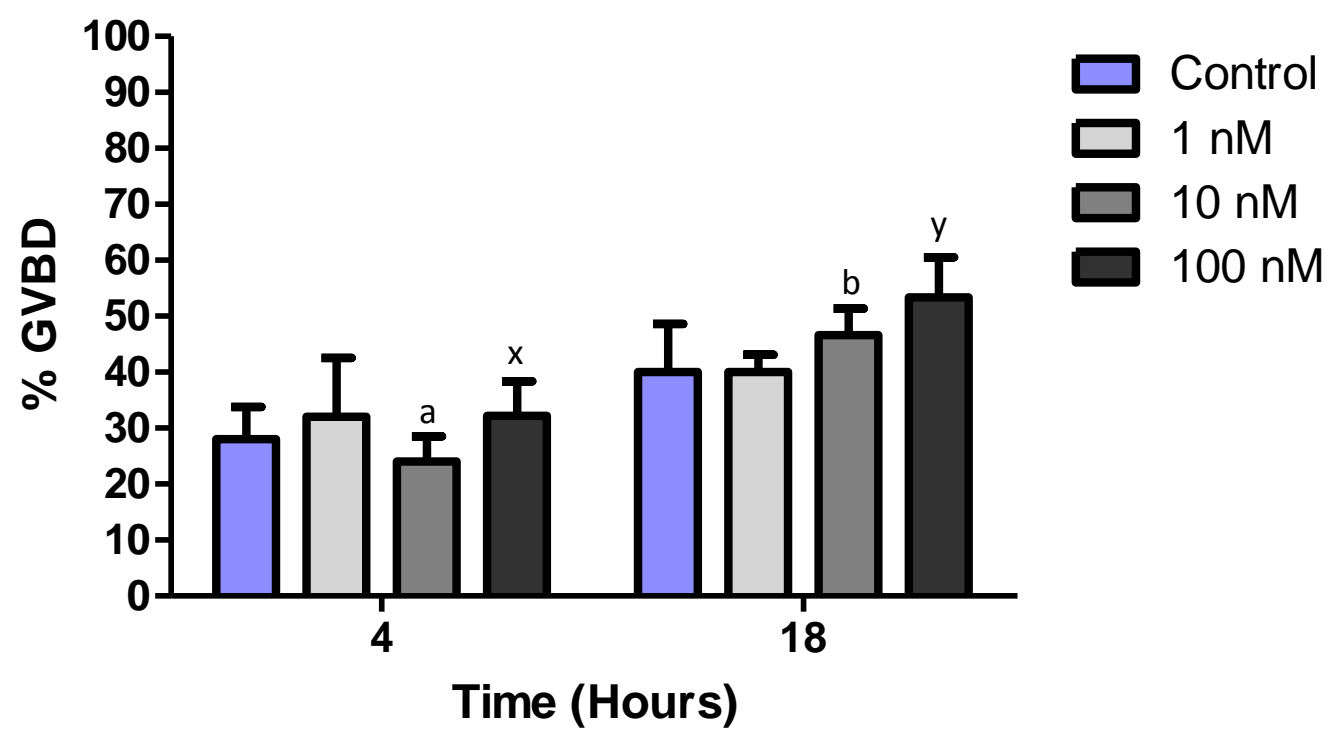

Figure 3-3: The proportion of oocytes that had initiated GVBD following the culture of rat COCs with 0 (control), 1,10 or $100 \mathrm{nM}$ CNP for 4 or 18 hours. For each replicate experiment, 15 COCs were cultured in each treatment for each time period. Bars represent mean percentage GVBD $\pm S E M$ of 5 replicate experiments ( $N=75$ per group). Chi-squared tests indicated a significant difference between the treatment groups assessed here $(p=0.0027)$. Fisher's exact test identified significant differences in proportions of oocytes that had initiated GVBD between the 4 and 18 hour incubation times in the 10 and $100 \mathrm{nM}$ dosage groups (as denoted by consecutive letter pairs, $p<0.05$ ). 


\subsubsection{The Effects of Increasing Doses of Oestradiol on GVBD in}

Rat COCs cultured in vitro

There was a significant difference in the proportion of oocytes that resumed meiosis as a result of treatment of rat COCs in vitro with $0,50,200$ or $1000 \mathrm{ng} / \mathrm{mL}$ oestradiol for either 4 or 18 hours (Figure 3-4). Fisher's exact tests revealed that a higher proportion of oocytes had initiated GVBD after 18 hours of incubation, compared with 4 hours of incubation in those COCs incubated with 200 and $1000 \mathrm{ng} / \mathrm{mL}$ of oestradiol ( $p=0.0207$ and $p=0.0321$, respectively).

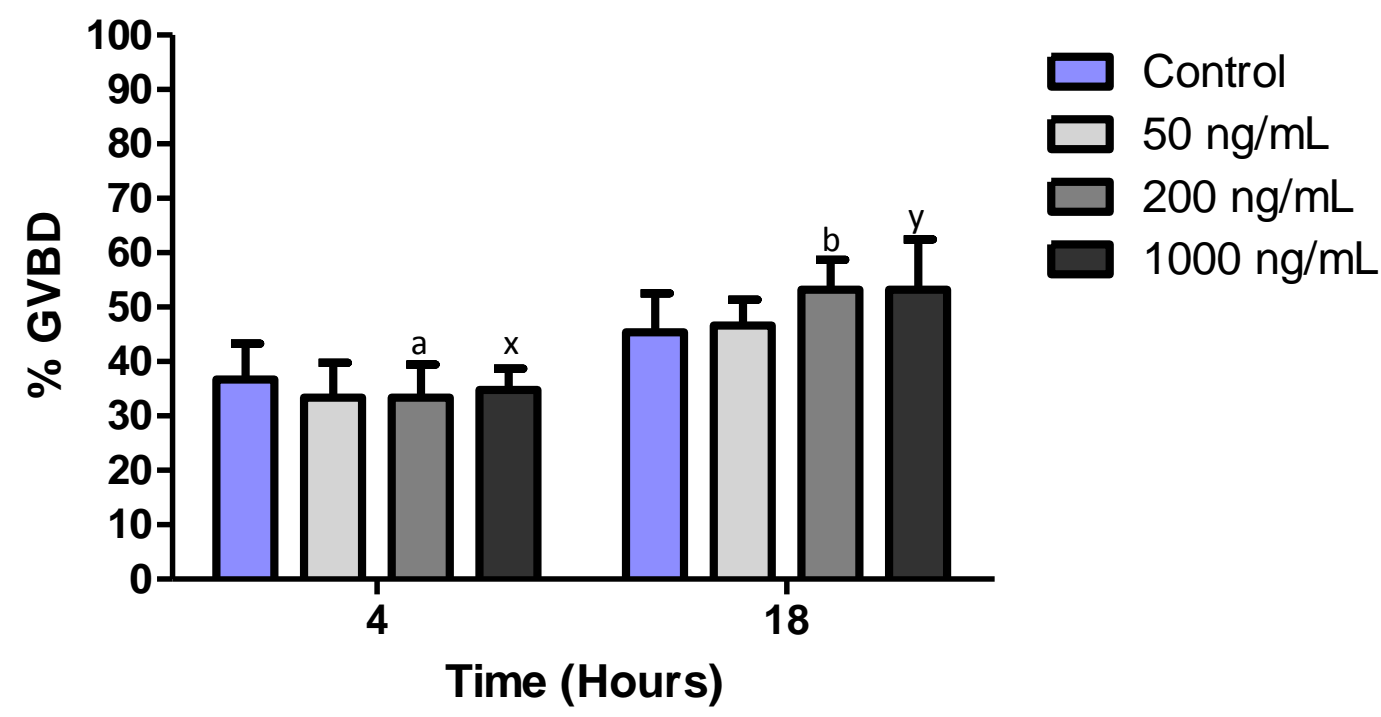

Figure 3-4: The proportion of oocytes that had initiated GVBD following the culture of rat COCs with 0 (control), 50,200 or $1000 \mathrm{ng} / \mathrm{mL}$ oestradiol for 4 or 18 hours. For each replicate experiment, $15 \mathrm{COCs}$ were cultured in each treatment for each time period. Bars represent mean percentage GVBD \pm SEM of five replicates ( $N=75-90$ per group). Chi-squared tests indicated a significant difference between the treatment groups $(p=0.0029)$. Fisher's exact test identified significant differences in the proportions of oocytes that had initiated GVBD between the 4 and 18 hour incubation times in the 200 and $1000 \mathrm{ng} / \mathrm{mL}$ treated group as denoted by consecutive letter pairs $(p<0.05)$.

\subsubsection{The Effects of Increasing Doses of Progesterone on GVBD} in Rat COCs cultured in vitro

There was a significant effect of treatment with different doses of progesterone on the proportion of oocytes that had initiated GVBD following the incubation of rat COCs with either 0, 50, 200 or $1000 \mathrm{ng} / \mathrm{mL}$ progesterone in vitro (Figure 3-5). Following an 18 hour incubation, the proportion of oocytes that had initiated GVBD had decreased in the $200 \mathrm{ng} / \mathrm{mL}$ treatment group when compared to the control group $(p=0.0130)$. Fisher's exact tests showed that a higher proportion of oocytes 
had initiated GVBD after 18 hours of incubation, compared with 4 hours of incubation in control COCs and in the COCs that were treated with $1000 \mathrm{ng} / \mathrm{mL}(\mathrm{p}=0.0068$ and $\mathrm{p}=0.0116)$.

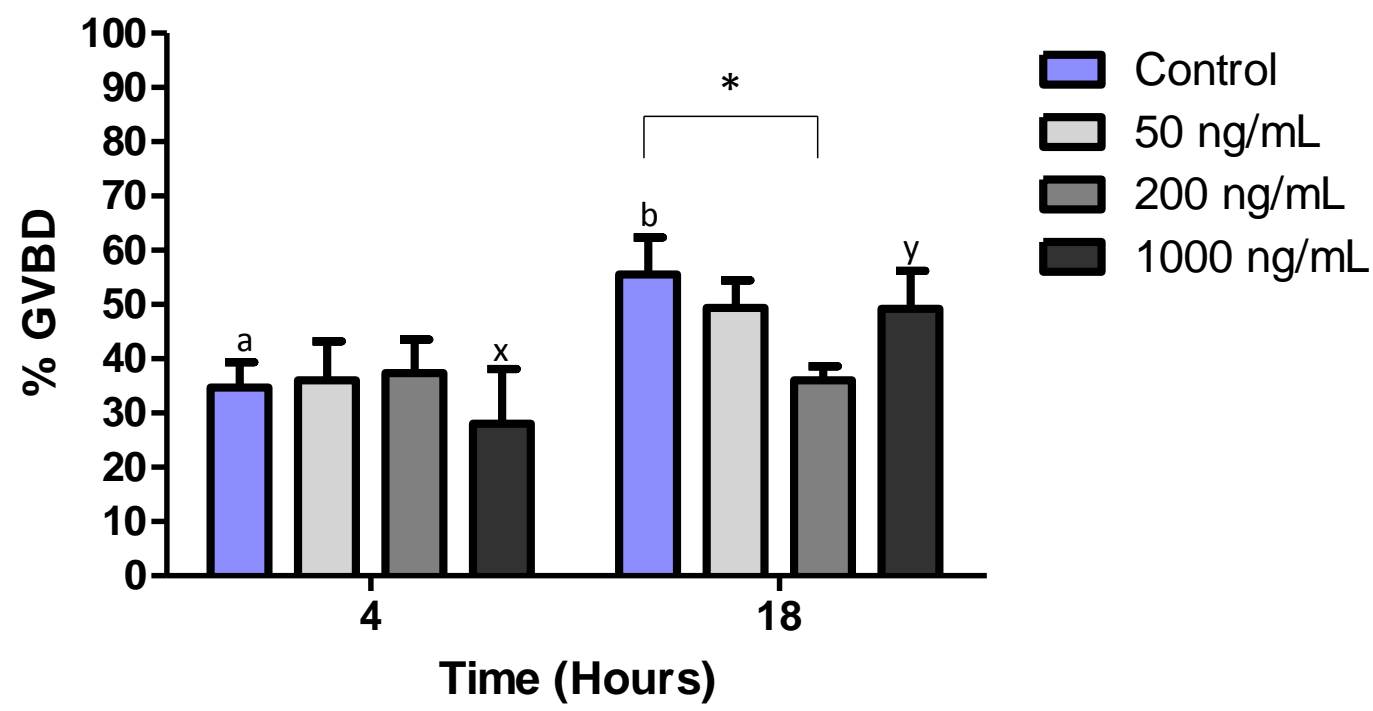

Figure 3-5: The proportion of oocytes that had initiated GVBD following the culture of rat COCs with 0 (control), 50,200 or $1000 \mathrm{ng} / \mathrm{mL}$ progesterone for 4 or 18 hours. For each replicate experiment, $15 \mathrm{COCs}$ were cultured in each treatment for each time period. Bars represent mean percentage GVBD \pm SEM of five replicates ( $N=75-90$ per group). Chi squared tests indicated an overall difference in the rate of initiation of meiotic resumption between the treatment groups $(p<0.01)$. Fisher's exact test identified a significant difference between the control COCs and the group of COCs treated with $200 \mathrm{ng} / \mathrm{mL}$ following an 18 hour incubation as indicated by * $\left({ }^{*} p<0.05\right)$. Furthermore, significant differences in proportions of oocytes that had initiated GVBD between the 4 and 18 hour incubation times in the control COCs and COCs treated with $1000 \mathrm{ng} / \mathrm{mL}$ was also identified as denoted by consecutive letter pairs, $(p<0.05)$.

\subsection{Outcomes from Optimisation Studies}

As a result of the optimisation studies presented here, subsequent experiments were performed under the conditions described below. The phosphodiesterase inhibitor solution was supplemented to all media for culturing the COCs in the gap junction assay. Therefore, this would include samples that were subsequently used for qPCR analyses and to assess the effects of treatments on the proportion of oocytes that had initiated GVBD in vitro.

As none of the doses of CNP and oestradiol, and only the $200 \mathrm{ng} / \mathrm{mL}$ dose of progesterone following an 18 hour incubation, had effect on the proportions of oocytes that initiated GVBD in cultured rat COCs, dosages were selected based on published data. For example, a previous study indicated that $100 \mathrm{nM}$ of CNP was 
extremely effective at maintaining meiotic arrest in cultured mouse and pig COCs (Zhang et al., 2010; Kawamura et al., 2011; Hiradate et al., 2013) and thus the concentration of $100 \mathrm{nM}$ CNP was selected for the subsequent experiments described herein. In terms of oestradiol and progesterone, a dose of $200 \mathrm{ng} / \mathrm{mL}$ was chosen as this is considered to be high but within the physiological range observed in rat, sheep and human follicular fluid (Goff and Henderson, 1979; McNatty et al., 1986; Westergaard et al., 1986). 


\section{Chapter 4: $\quad$ Results -The Effects of C-Type Natriuretic Peptide (CNP) and Steroid Hormones on CNP/NPR2 signalling in Rat COCs cultured in vitro}

\subsection{The Effects of Follicular-secreted Factors on Gap Junction Communication in Rat COCs cultured in vitro}

The results of the following experiments addressed the first aim that was to assess the effects of CNP and oestradiol on gap junction communication in rat COCs and the results are illustrated in Figure 4.1. The effects of progesterone as an alternative steroid hormone were also assessed.

There was a main effect $(p<0.0001)$ of incubation time on the levels of fluorescent dye measured within oocytes. Overall, fluorescent dye transfer into the oocyte decreased after 19 hours of incubation, when compared those incubated for 1 and 5 hours. This reduction in dye transfer to oocytes after 19 hours incubation was observed for all treatment groups (depicted by different consecutive letters in Figure 4.1).

There was also a main effect $(p=0.0308)$ of treatment on the levels of fluorescent dye measured in oocytes. Statistical post-hoc tests revealed that this observation was due to a reduction in fluorescence values in those oocytes that were cultured with CNP alone when compared with control oocytes and was most marked after 19 hours incubation (depicted by * in Figure 4.1).

There was no significant interaction between treatment and incubation time on the levels of fluorescent dye in oocytes. 


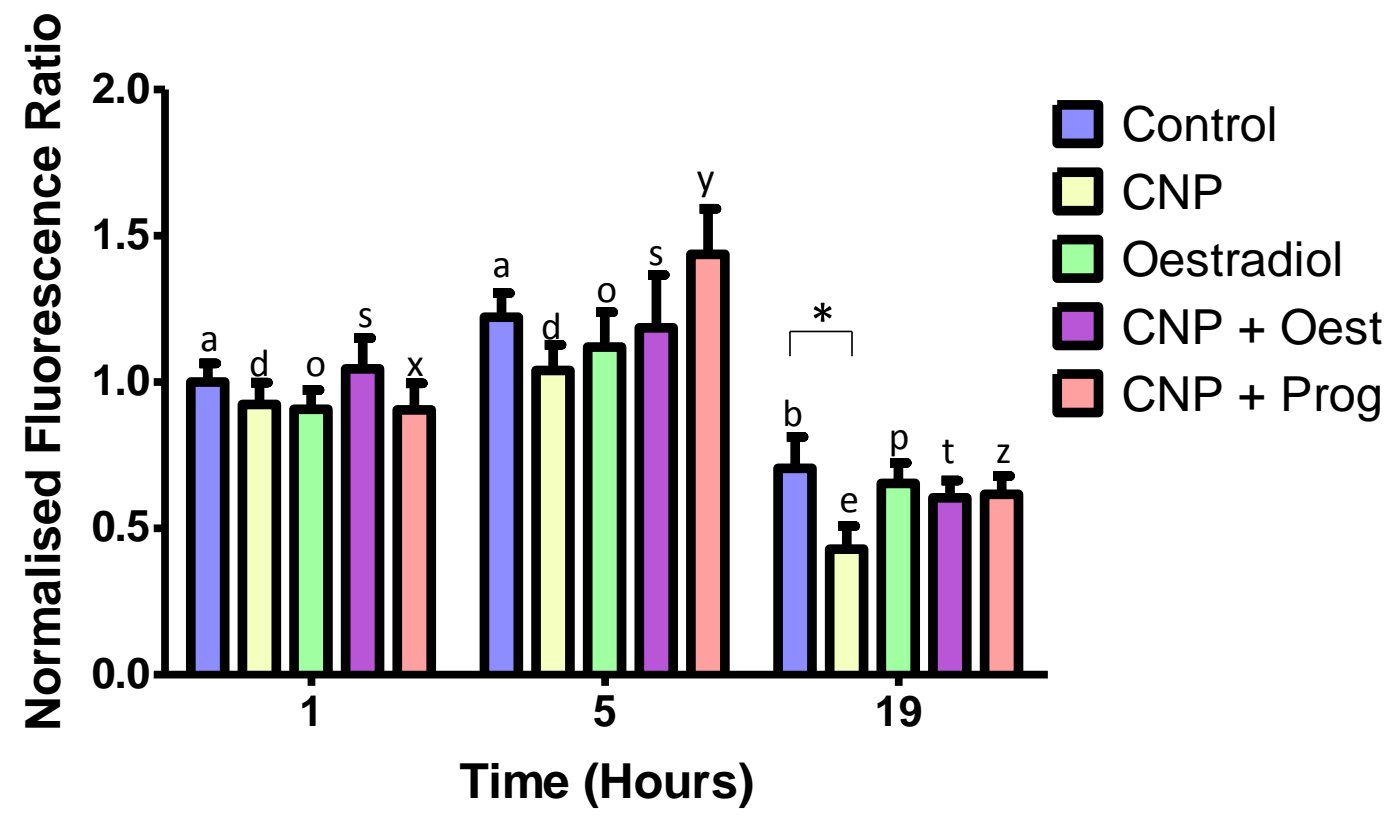

Figure 4-1: Mean fluorescent values \pm SEM in oocytes following in vitro culture of rat COCs with media alone (control), CNP, oestradiol, CNP and oestradiol in combination, and CNP and progesterone in combination for either 1,5 or 19 hours. Values were normalised to the average fluorescence value of the controls after 1 hour incubation. For each replicate experiment, 8-10 COCs were cultured in each treatment for each time period ( $\mathrm{N}=45-50$ per group). A significant effect of treatment $(p=0.0308)$ and incubation time $(p<0.0001)$ was observed. Statistical posthoc tests indicated a reduction $(p=0.0056)$ in oocyte fluorescence in all treatment groups after 19 hours of incubation as denoted by different consecutive letters. Furthermore, there was less fluorescence $(p<0.05)$ present in oocytes cultured with CNP alone compared to the control group, particularly after 19 hours of incubation as depicted by *. 


\subsection{The Effects of CNP and Oestradiol on cGMP levels in COCs cultured in vitro}

The results of the following experiments addressed the second aim that was to assess the effects of CNP and oestradiol on cGMP levels within rat COCs and are illustrated in Figure 4-2.

As it was only possible to perform two replicates, statistical tests were not carried out on the data for the cGMP assay. In addition, although an endogenous control was included in each of the replicates, the control was not measurable in the second assay. However, because each replicate assay contained each of the treatment groups, comparisons were made within replicates. All results from this assay should thus be interpreted with caution. Notwithstanding, the data presented in Figure 4-2 indicated that CGMP levels in COCs in all of the treatment groups were higher when compared to cGMP levels in control COCs.

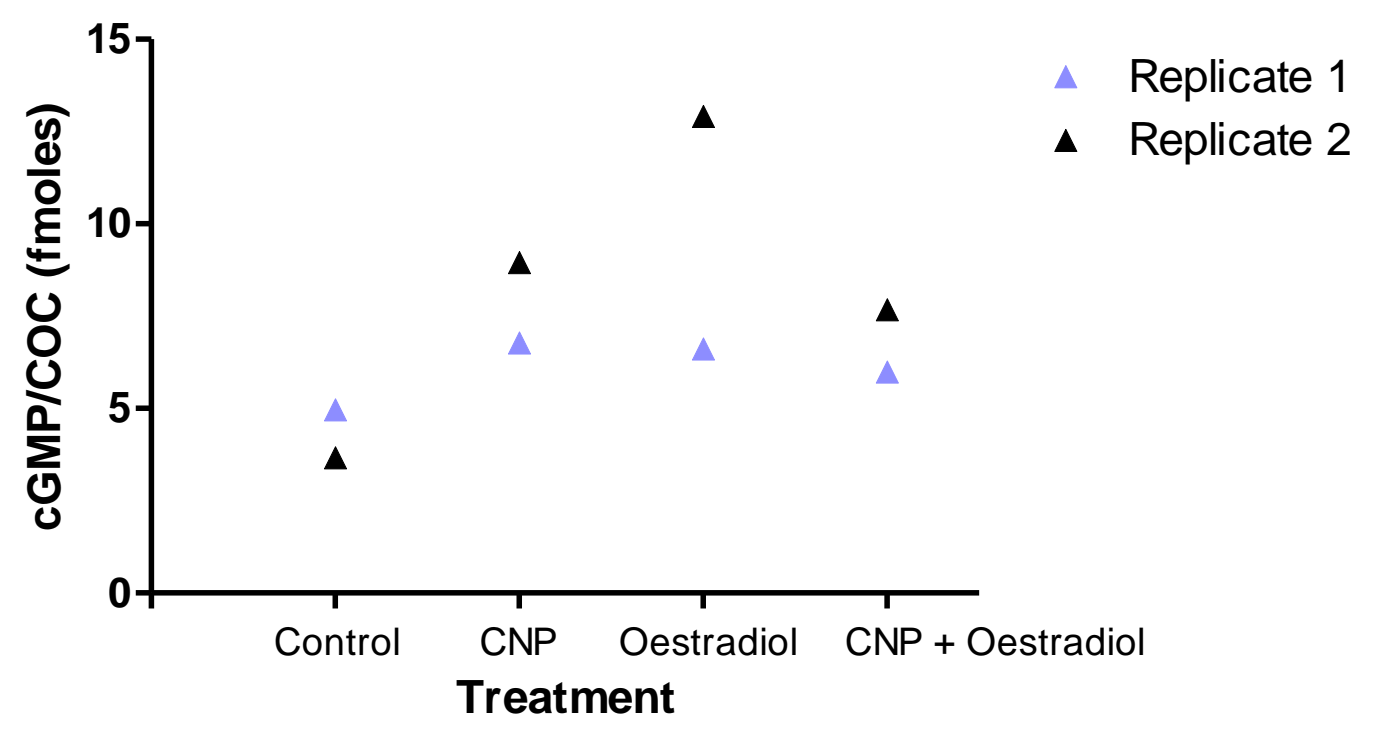

Figure 4-2: The levels of CGMP (fmole) per COC following in vitro culture of rat COC pools (100 COCs) with CNP and oestradiol, alone and in combination for 5 hours. For each replicate experiment, $100 \mathrm{COCs}$ were cultured for 5 hours with media alone (control), CNP, oestradiol or CNP and oestradiol in combination ( $N=2$ ).cGMP levels in these COC pools were then measured using a direct competitive immunoassay. 


\subsection{The Effects of CNP and Steroid Hormone Treatments on}

Cumulus Cell-Derived Gene Expression in Rat COCs Cultured in vitro

The results of the following experiments addressed the third aim that was to assess the effects of CNP and oestradiol on mRNA expression levels of key cumulus cellderived candidate genes involved in the hypothesised regulatory model of meiotic arrest. All gene expression values were corrected against a previously validated reference gene (Rp/19) (Crawford and McNatty, 2012; Ekart et al., 2013).

During the $\mathrm{qPCR}$ optimisation process, $P d e 4 b$ was identified as being expressed at very low abundance even in pools of 50 COCs, despite high levels of Rp/19 expression. Therefore, the routine procedures for optimising and validating the gene $P d e 4 b$ for quantitative analyses were unable to be carried out accurately as the expression levels were outside the sensitivity of the qPCR assay. Despite this, $P d e 4 b$ primers and probes were included within a quadriplex reaction (together with Pde4d, Npr2 and Rp/19) to determine any marked effects on expression of Pde4b due to treatment or incubation time. However, in the large majority of cumulus cell samples collected, the expression levels of $P d e 4 b$ were undetectable regardless of the experimental conditions explored within this study.

The intra-assay and inter-assay coefficient of variation (CV) was calculated for Pde $4 d$ and Npr2 using the $\Delta \mathrm{C}_{\mathrm{T}}$ values for the calibrator samples in each qPCR run (the $\mathrm{C}_{\mathrm{q}}$ value for RPL19 subtracted from the $\mathrm{C}_{\mathrm{q}}$ value for the gene of interest). The intra-assay and inter-assay CV for Pde4d were $2.69 \%$ and $0.8 \%$, respectively. Likewise, the intra-assay and inter-assay CV for Npr2 were $1.7 \%$ and $1.67 \%$, respectively.

\subsubsection{The Effects of CNP and Steroid Hormone Treatments on} Npr2 mRNA Expression in Rat Cumulus Cells

The mRNA expression levels of cumulus cell-derived Npr2 from COCs incubated with media alone (control), CNP, oestradiol, CNP and oestradiol in combination, and CNP and progesterone in combination for either 1, 5 or 19 hours are illustrated in Figure 4.3. 
There were main effects, but no interaction, of both treatment $(p<0.001)$ and incubation time $(p=0.047)$ on Npr2 expression levels. Furthermore, when compared to the control group, the median expression levels of Npr2 in cumulus cells of COCs incubated with oestradiol, CNP and oestradiol in combination, and CNP and progesterone in combination were significantly higher $(p<0.05)$ than that in controls after 5 and 19 hours incubation, as depicted by * in Figure 4.3. Finally, statistical post-hoc test indicated that the cumulus cells within COCs cultured with CNP had increased Npr2 expression with time in incubation, as depicted by different letters in Figure 4.3.

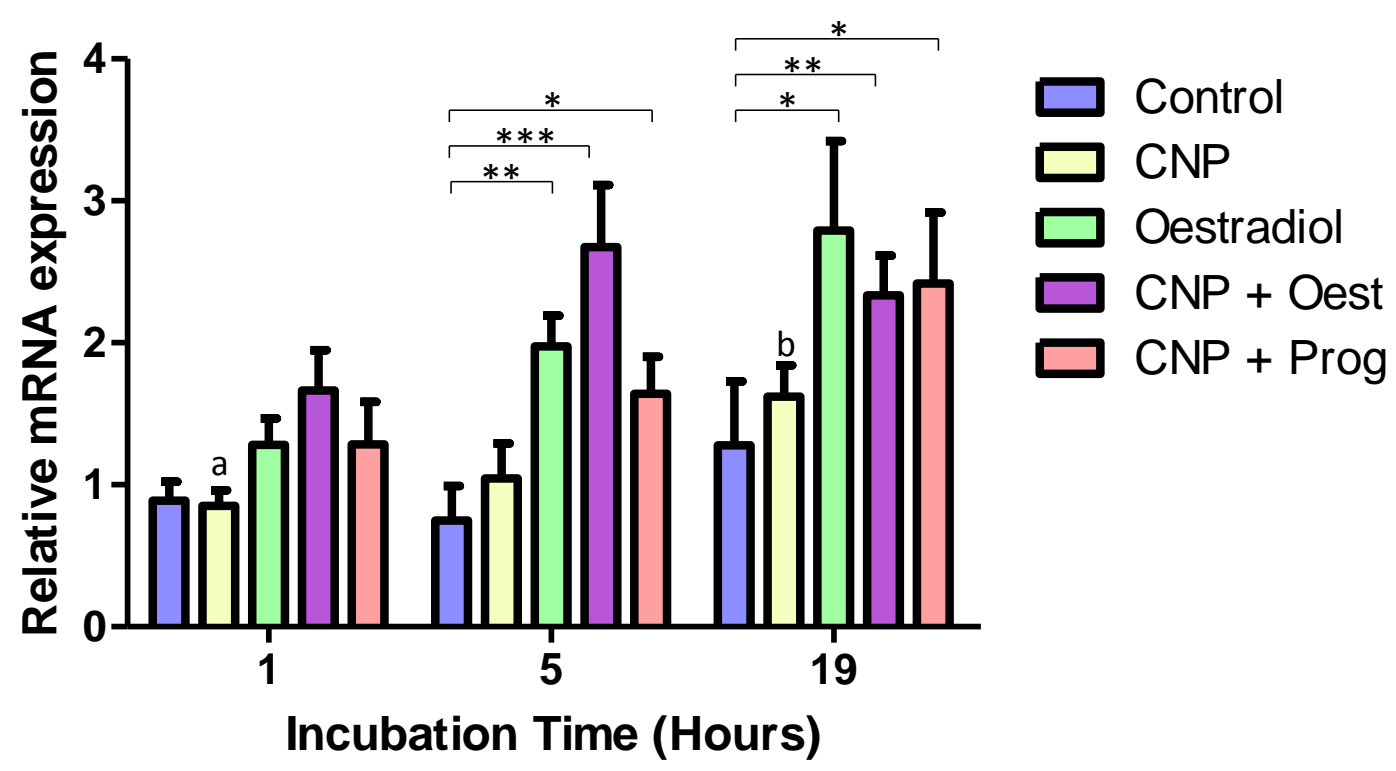

Figure 4-3: Mean relative mRNA expression levels \pm SEM of Npr2 in cumulus cells of rat COCs incubated with media alone (control), CNP, oestradiol, CNP and oestradiol in combination, and CNP and progesterone in combination for either 1,5 or 19 hours. For each replicate experiment, three cumulus cell samples collected for the gap junction assays were randomly chosen from each treatment group at each time point for subsequent gene expression analysis $(\mathrm{N}=11-15$ per group). A significant effect of treatment $(\mathrm{p}<0.001)$ and incubation time $(p=0.047)$ was observed. Note that Npr2 expression levels in COCs incubated with CNP increased significantly $(p<0.05)$ over time, as denoted by the different letters. Also note that Npr2 expression levels in COCs incubated with oestradiol, CNP and oestradiol combined, and CNP and progesterone combined were significantly higher than the controls after 5 and 19 hours of incubation, as denoted by ${ }^{*}\left({ }^{*} p<0.05,{ }^{* *} p<0.01,{ }^{* * *} p<0.001\right)$.

\subsubsection{The Effects of CNP and Steroid Hormones on Pde4d mRNA expression in Rat Cumulus Cells}

The mRNA expression levels of cumulus cell-derived Pde4d from COCs incubated with media alone (control), CNP, oestradiol, CNP and oestradiol in combination, and 
CNP and progesterone in combination for either 1, 5 or 19 hours are illustrated in

Figure 4.4.

There were main effects, but no interaction, of both treatment $(p<0.001)$ and incubation time $(p<0.001)$ on Pde $4 d$ mRNA levels. Treatment effects were observed at each incubation time point ( $p<0.05$ for 1 and 19 hours; $p<0.01$ for 5 hours as depicted by * in Figure 4.4) but further statistical post-hoc analyses indicated that only COCs incubated for 1 hour with CNP and oestradiol combined expressed higher ( $\mathrm{p}<0.05,{ }^{*}$ in Figure 4.3) Pde4d mRNA levels than that of controls. Further statistical comparisons to identify incubation time differences within treatment groups indicated that in the control and the oestradiol-treated groups, Pde4d expression levels decreased with time. as depicted by different consecutive letters in Figure 4.4.

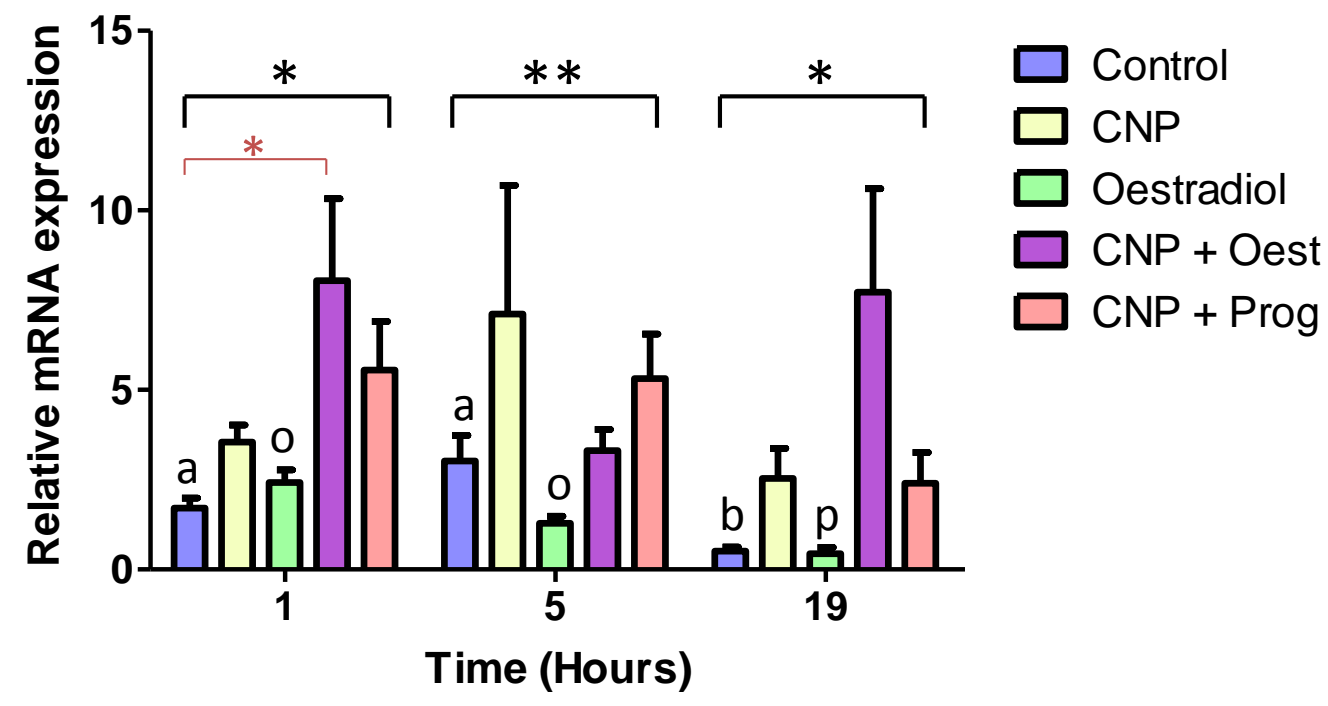

Figure 4-4: Mean relative mRNA expression levels \pm SEM of Pde4d in cumulus cells of rat COCs incubated with media alone (control), CNP, oestradiol, CNP and oestradiol in combination, and CNP and progesterone in combination for either 1, 5 or 19 hours. For each replicate experiment, three cumulus cell samples collected for the gap junction assays were randomly chosen from each treatment group at each time point for subsequent gene expression analysis $(\mathrm{N}=11-15$ per group). A significant effect of both treatment $(p<0.001)$ and incubation time $(p<0.001)$ were observed. Within each of the incubation times, there were significant differences between treatments, as indicated by *. Statistical post-hoc tests indicated significantly higher expression levels $(p<0.05)$ of Pde4d in COCs incubated with CNP and oestradiol combined, compared to controls after 1 hour incubation (depicted by *). Within the different treatment groups, Pde4d mRNA levels decreased with time $(p<0.05)$ in the COCs incubated with media alone (controls) and with oestradiol alone as indicated by different consecutive letters $(p<0.05)$. 


\subsection{The Effect of CNP and Steroid Hormones on GVBD in Rat}

\section{COCs cultured in vitro}

The results of the following experiments addressed the fourth aim that was to assess the effects of CNP and oestradiol on the prevention of spontaneous meiotic resumption in COCs extracted from follicles and cultured in vitro by assessing the proportion of oocytes that had a visible GV with increasing time in culture.

The proportion of oocytes that had initiated GVBD in cultured rat COCs was found to be different in the treatment groups assessed in this study (Figure 4.5). In particular, a significant difference was identified in the GVBD rate between the treatment groups following a 5 hour incubation $(p=0.0042)$. Within the groups that had been incubated for 5 hours with the treatments, only the CNP and oestradiol in combination and the CNP and progesterone in combination had significantly increased rates of meiotic resumption when compared to the controls $(p=0.0063$ and $\mathrm{p}=0.0243$, respectively). Note that these COCs were incubated in media containing phosphodiesterase inhibitors.

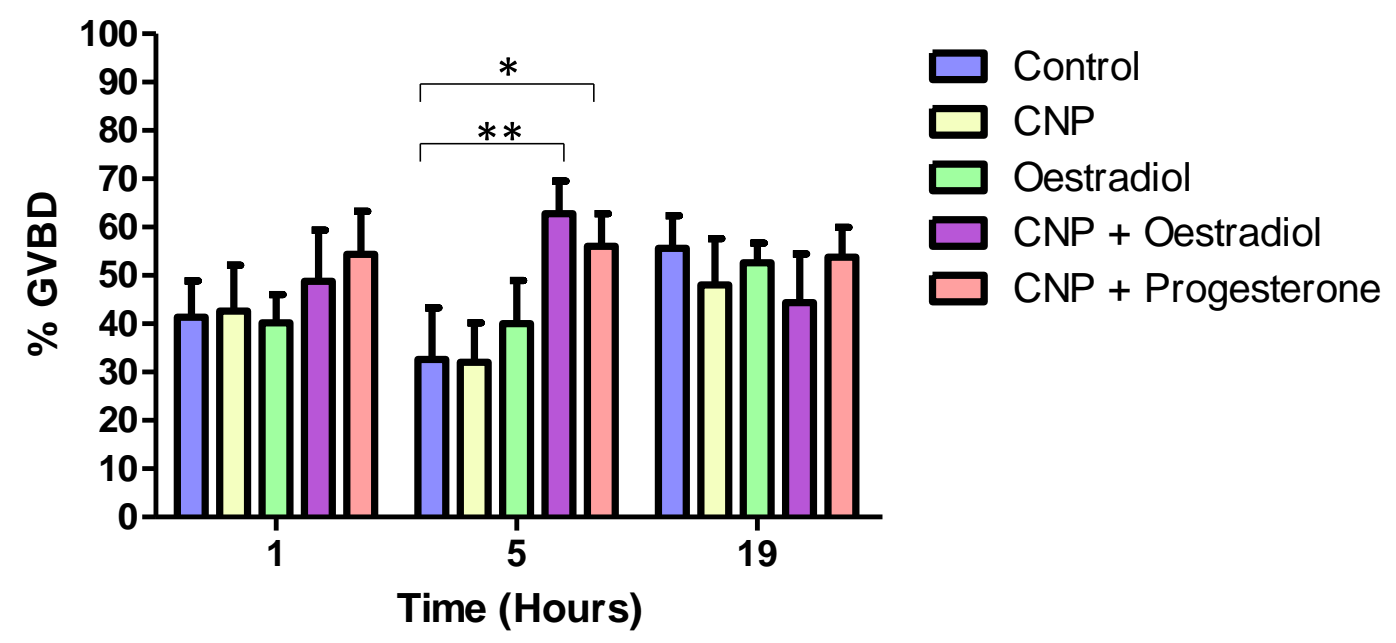

Figure 4-5: Mean proportions (\%) \pm SEM of rat oocytes with or without (GVBD) a visible germinal vesicle in rat COCs incubated with media alone (control), CNP, oestradiol, CNP and oestradiol in combination, and CNP and progesterone in combination for either 1, 5 or 19 hours. For each replicate experiment, 8-10 COCs were cultured in each treatment for each time period ( $\mathrm{N}=45-50$ per group). An effect of treatment regime on the duration of meiotic arrest was found $(p=0.0265)$. Furthermore, Chi squares tests indicated that there was a difference between the treatment groups within the 5 hour incubation group $(p=0.0042)$. This difference was found when comparing the rate of GVBD in the CNP and oestradiol combination, and CNP and progesterone combination treated COCs with control COCs as indicated by * $\left({ }^{*} p<0.05\right.$, $\left.{ }^{* *} p<0.01,{ }^{* * *} p<0.001\right)$. 


\subsubsection{The Effect of CNP and Oestradiol on the Duration of Meiotic}

Arrest without Phosphodiesterase Inhibitor

\section{Supplementation}

The combined effects of CNP and oestradiol on the rates of meiotic resumption were assessed without phosphodiesterase inhibitor supplementation in order to determine whether CNP and oestradiol could indeed modulate the rate of meiotic resumption and whether the phosphodiesterase inhibitor solution was altering the sensitivity of rat COCs cultured in vitro to meiosis inhibiting compounds (Figure 4-6).

The proportion of rat oocytes that had initiated GVBD was significantly different between the groups assessed in this study $(p<0.0001)$. Following a 5 hour incubation, the oocytes in the control group had significantly higher levels of GVBD compared to freshly isolated oocytes (control at 0 hours) $(p<0.0001)$. Additionally, the COCs incubated for 5 hours with CNP and oestradiol in combination had a significantly lower rate of meiotic resumption when compared to the control group $(p=0.0329)$.

For further investigation of the effects of CNP and oestradiol on the timing of meiotic resumption, an orcein staining technique was used. Despite being unable to investigate the stage of meiosis in all of the oocytes used in the above experiment, all oocytes that were assessed using this technique confirmed that the original assessment of the meiotic status (GV or GVBD) of these oocytes was correct (Figure 4-7 and Figure 4-8). 


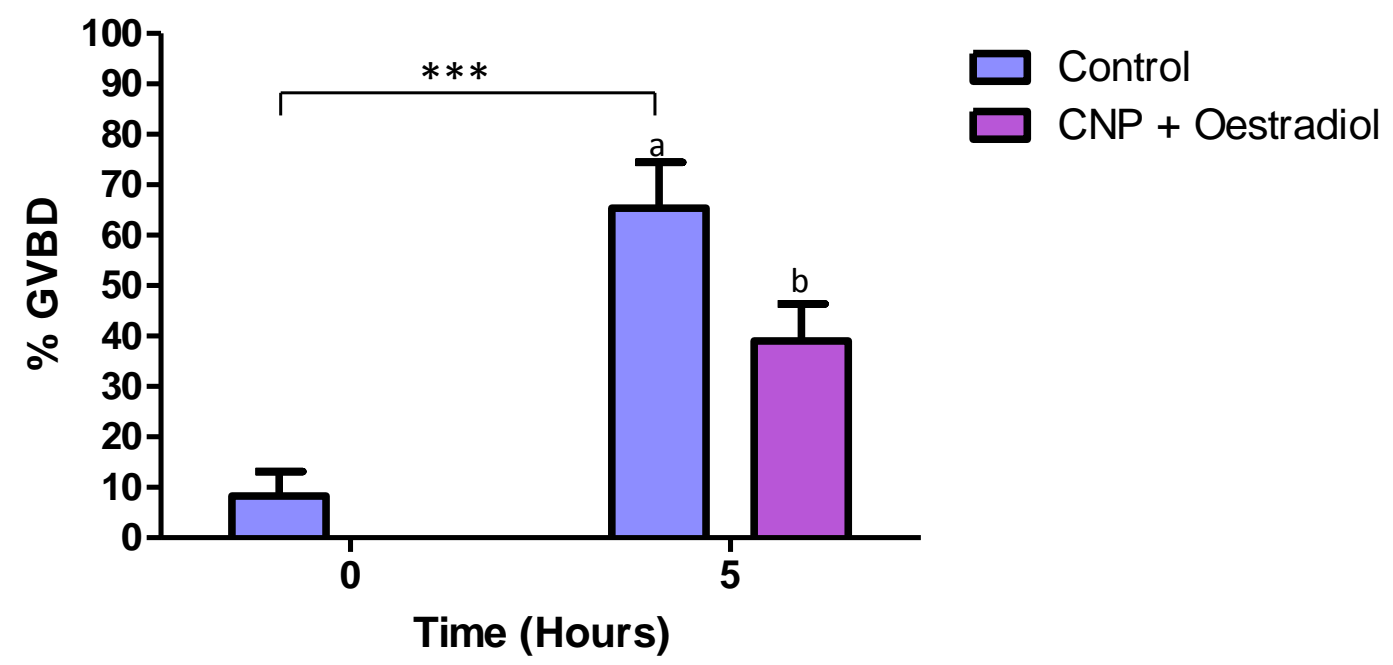

Figure 4-6: Mean proportions (\%) \pm SEM of rat oocytes with or without (GVBD) a visible germinal vesicle of rat COCs that were assessed immediately following collection, or following a 5 hour incubation with media alone (control), or CNP and oestradiol in combination. For each replicate experiment, 11-12 COCs were cultured in each treatment for each time period $(\mathrm{N}=35-$ 36 per group). Fisher's exact test identified a significant difference in the rate of initiation of GVBD between the treatment groups $(p<0.0001)$. Note a significant increase in GVBD in the control group over time ( $\left.{ }^{*} p<0.05,{ }^{\star *} p<0.01,{ }^{* * *} p<0.0001\right)$. A significant difference between the treatment groups was found using Fisher's exact test, as indicated by the different consecutive letters $(p<0.05)$.

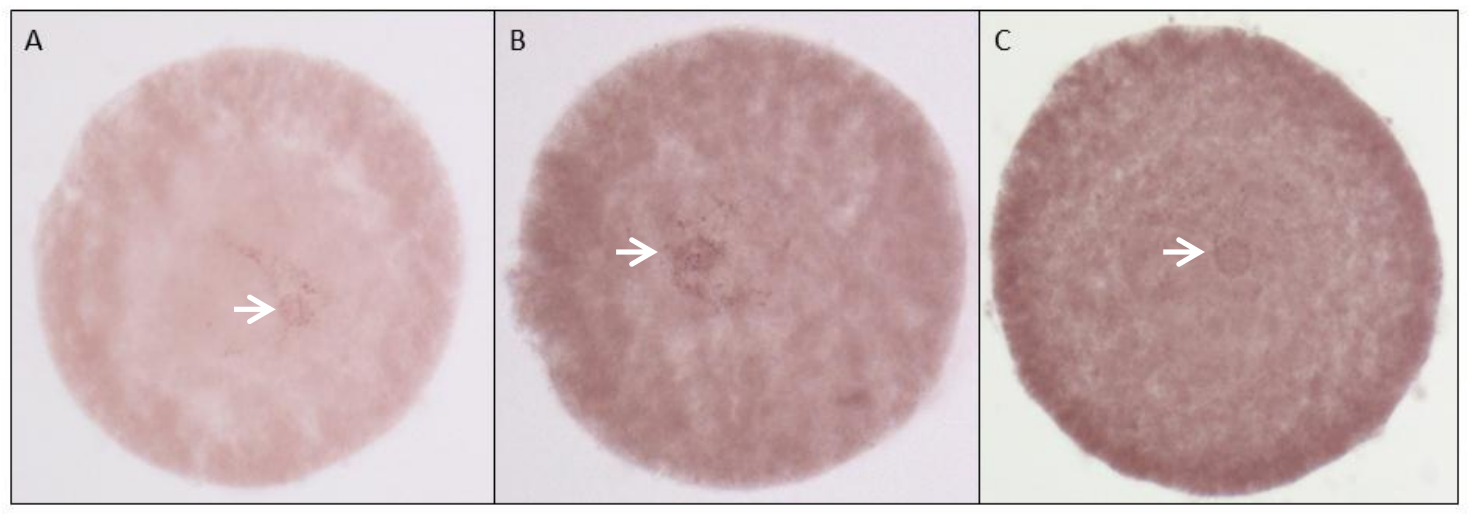

Figure 4-7: Photomicrographs of denuded rat oocytes in the germinal vesicle (GV) stage stained with orcein. COCs used in the experiment depicted in Figure 4-6 were assessed for the presence of a GV and then stained using the orcein staining protocol. The visible nucleolus (a characteristic of GV stage oocytes) is indicated by the white arrow. In A and B filamentous chromatin can be seen in the cytoplasm around the nucleolus but this is not clear in $\mathrm{C}$ due to the oocyte being more darkly stained. 


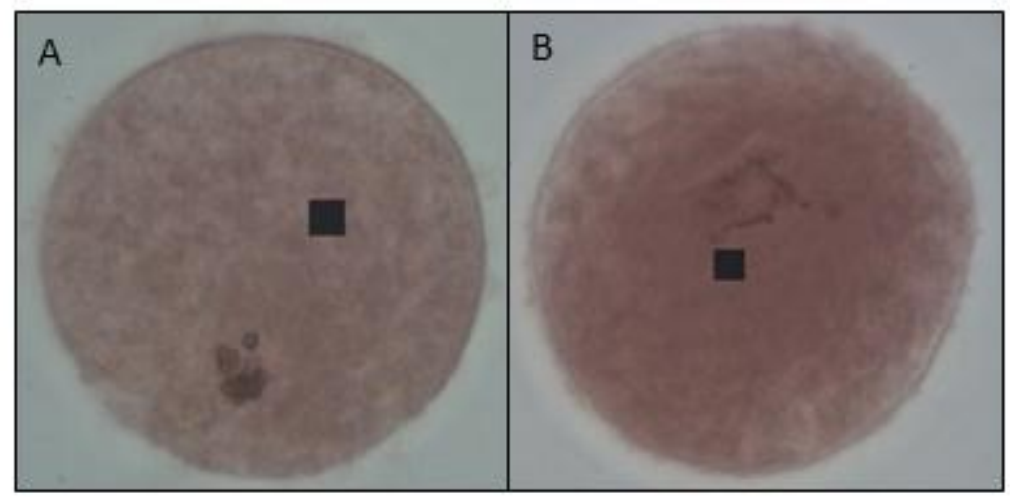

Figure 4-8: Photomicrographs of denuded rat oocytes that have initiated germinal vesicle breakdown (GVBD). COCs used in the experiment depicted in Figure 4-6 were assessed for the presence of a GV and then stained using the orcein staining protocol. The oocyte in A has initiated GVBD; the chromosomes are condensed indicating the end of meiotic arrest and prophase $I$. The oocyte in B has initiated GVBD and appears to be at metaphase I or anaphase I stage of meiosis. Note the black square pictured above functioned as part of the CRAIC fluorescence detection system and could not be removed in these photomicrographs. 


\section{Chapter 5: Discussion}

The overall aim of this study was to elucidate the validity of a hypothesised regulatory pathway, illustrated in Figure 1-5, to explain the regulation of meiotic arrest in a rat model. In this hypothesised mechanism, CNP activates its high-affinity receptor, NPR2, located on cumulus cells to stimulate the synthesis of cGMP. Cyclic GMP is transferred to the oocyte via gap junctions where it slows the hydrolysis of CAMP by PDE3A. In antral follicles, the granulosa cells produce oestradiol, which increases the numbers of NPR2 which further increases cGMP production resulting in a prolonged inhibition of meiotic resumption. In order to assess the validity of this hypothesis in the rat, this study investigated four fundamental components of this regulatory mechanism. The first component of the pathway investigated was that of gap junction communication. Specifically, CNP and oestradiol were assessed for short- (4 and 5 hour incubations) and long- (18 and 19 hours) term effects on gap junction permeability. Secondly, in terms of this hypothesised model, it was important to determine whether treatment of rat COCs with CNP and oestradiol alone and in combination resulted in measurable increases in cGMP levels in COCs The third component investigated was whether CNP and oestradiol were able to modulate, following short and long incubations with COCs, the expression levels of the key genes Npr2, Pde4b and Pde4d. The final component investigated in this study were the effects of CNP and oestradiol, alone and in combination, on the duration of meiotic arrest and whether this was delayed in response to the aforementioned treatments. Only by investigating these four aspects, can the validity of the hypothesised pathway be vigorously assessed in the rat model.

Gap junction permeability is critical to the hypothesised model. If gap junction communication between the cumulus cells and oocyte is impaired, any CNP-mediated changes in cGMP levels within cumulus cells may not relayed into the oocyte to assist in the inhibition of CAMP hydrolysis by PDE3A. The results presented herein reveal that in spite of a significant decrease in gap junction permeability in cultured COCs with time, it is possible that there is sufficient gap junction communication to allow regulatory molecules, such as cGMP to be transferred to the oocytes at levels that are sufficient to prevent meiotic resumption. A previous report on bovine gap junction permeability indicated that meiotic 
resumption in response to loss of gap junction communication occurred once calcein transfer dropped to below $40 \%$ of the original levels measured (Thomas et al., 2004). Therefore, while none of the treatments increased gap junction permeability, this study provides an indication that in rat COCs, sufficient gap junction permeability is maintained to allow for the transfer of CGMP to the oocyte even following 19 hours of culture. The results presented in this study are in agreement with previous reports in a number of mammalian species indicating reduced gap junction permeability in COCs over time, especially following prolonged ( $\geq 18$ hours) in vitro culture (e.g. in rats, Campen, 2013; pigs, Sasseville et al., 2009; and cows, Thomas et al., 2004).

As discussed previously, the basis of the hypothesised regulatory model was that cGMP levels increased in both the cumulus cell and oocyte compartments of mouse COCs following treatment with CNP. Interestingly, previous evidence indicated that treatment with CNP alone increased CGMP levels in freshly isolated COCs in both the cumulus cell and oocyte compartments, but this effect was transient. In order to elicit sustained increases in cGMP levels, treatment with a combination of CNP and oestradiol was required (Zhang et al., 2011). Moreover, it has also been shown that both cGMP and CNP protein levels and Npr2 mRNA are modulated during oestrous cycling in the rat (Jankowski et al., 1997; Gutkowska et al., 1999). In particular, the highest levels are observed around proestrous, indicating that high levels of oestradiol influence cGMP levels and that it is possible that this occurs via the pathway being investigated in this report. The results presented herein provide an indication that CNP may increase CGMP levels in COCs, and it also indicates that oestradiol may also modulate cGMP levels as well. Due to logistical constraints and the limited amount of time available to optimise this assay, only two replicates were performed. In order to be able to conclusively determine the effect of these treatments on CGMP levels in COCs, further investigation would be required. However, in combination with the results presented for the gene expression studies for Npr2, the results of the CGMP assay give a preliminary indication that CGMP levels were increased in response to treatment of rat COCs with CNP and oestradiol.

To ascertain indirectly the levels of cGMP within the cumulus cells and to establish a role of oestradiol in the hypothesised pathway, mRNA expression levels of Npr2 were quantified in cultured rat COCs. While there are a number of other guanylyl cyclase receptors (both membrane bound and soluble) that have been identified in 
rat and mouse follicles, these are significantly lower in abundance and have been shown to contribute little to the follicular cGMP levels when compared to NPR2 (Noubani et al., 2000; Robinson et al., 2012). Moreover, Npr2 mRNA expression has been shown to be modulated during the oestrous cycle and particularly in response to gonadotropins (Jankowski et al., 1997; Gutkowska et al., 1999; Kawamura et al., 2011; Robinson et al., 2012). The results presented herein reveal that exposure of COCs to oestradiol alone, CNP and oestradiol in combination, and CNP and progesterone in combination increased Npr2 mRNA expression levels following 5 and 19 hours of incubation. These results are in agreement with previous reports in which treatment of mouse and rat COCs with oestradiol and DES increased Npr2 mRNA expression levels in the cumulus cells, compared to untreated controls (Noubani et al., 2000; Zhang et al., 2011). Although treatment with progesterone alone had previously been shown to have no effect on Npr2 mRNA expression levels (Zhang et al., 2011), the current study showed that treatment of rat COCs with CNP and progesterone in combination increased cumulus cell Npr2 mRNA levels. It is important to note however that other studies used significantly lower doses of steroid hormones ( $\sim 7$ fold less of oestradiol and $\sim 6$ fold less of progesterone). Moreover, in this study, only cumulus cells from the CNP-treated group showed increased Npr2 mRNA expression over time. This could indicate that CNP alone is able to modulate Npr2 mRNA levels over time and may explain why in the study described herein, treatment with CNP and oestradiol had a greater effect than oestradiol alone, and that CNP and progesterone in combination increased Npr2 levels as well. It would have been particularly useful to assess the effects of progesterone alone on Npr2 expression in cultured cumulus cells in this study however time and logistical constraints deemed this not possible.

It is widely accepted that phosphodiesterases play an integral role in the regulation of meiotic resumption both in vitro and in vivo. However the effects of steroid hormones and phosphodiesterase inhibitors on phosphodiesterase activity and the duration of meiotic arrest are not well understood in the rat. The phosphodiesterase isoforms PDE4B and PDE4D have been identified in the follicular somatic cells of rats. The gene expression results reported herein indicate that Pde $4 b$ mRNA levels are expressed in very low abundance. While it was possible to measure Pde4b mRNA expression levels in larger pools of COCs, it was not possible in cumulus 
cells derived from a single COC. Nevertheless, this study has confirmed that $P d e 4 b$ mRNA is expressed in rat cumulus cells, albeit at very low levels.

From previous reports, there is strong evidence to suggest that PDE4D is influential in the regulation of meiotic resumption. Indeed, the loss of PDE4D function significantly affects female fertility as studied in a number of mouse knockout models and this is postulated to be due to disruption of the temporal pattern of cAMP levels (Jin et al., 1999). This evidence also includes the up-regulation of Pde4d mRNA and increased cAMP-hydrolysing activity in granulosa cells under gonadotropin stimulation (Jin et al., 1999; Park et al., 2003). This study reported herein confirmed that $P d e 4 d$ is expressed in rat cumulus cells and that Pde $4 d$ expression levels varied significantly over the different incubation times and in response to the various treatments. However overall, the treatments that consistently increased Pde4d mRNA levels all contained CNP (i.e. CNP alone, CNP and oestradiol combined, and CNP and progesterone combined). Moreover, CNP and oestradiol combined resulted in the largest increase in Pde4d mRNA, compared to that in controls, after 1 and 19 hours in culture. The expression levels of Pde $4 d$ in the control and oestradioltreated groups were the only groups that changed significantly with time in culture. Both of these groups showed a similar pattern of expression whereby a decrease in expression was observed following the 19 hours incubation, compared to that after 1 and 5 hours incubation. It is possible that in the other groups, the addition of CNP to the treatments may have masked this effect through modulation of cumulus cellderived cGMP and perhaps cAMP levels that may stimulate Pde4d mRNA expression levels.

The differential responsiveness of PDE4D to signalling by LH and FSH could indicate a mechanism by which increases in cAMP result in different outcomes in response to these signals (Jin et al., 1999; Park et al., 2003). Following FSH and LH stimulation in mice, it has been shown that Pde $4 d$ mRNA is upregulated and this is thought to be important for ensuring that concomitant increases in cAMP are transient (Park et al., 2003). The consensus is that the specificity of the gonadotropin signal is encoded in both fluctuations in the levels of cAMP in the follicle as well as the temporal patterns of cAMP concentration fluctuations. Park et al. (2003) hypothesised that due to the fact that $P d e 4 d^{--}$mice are unresponsive to $\mathrm{LH}$ signalling but still responsive to adenylyl cyclase stimulation that the impairment in 
$\mathrm{LH}$ signalling must be due to desensitisation or down-regulation of the $\mathrm{LH}$ receptor due to loss of PDE4D function. Therefore, evidence from this, and previous, studies support the notion that PDE4D is most likely to be regulated by a number of different pathways that are involved in the regulation of cAMP levels in the follicle, including gonadotropin signalling pathways (Park et al., 2003) and possibly the CNP/NPR2 regulatory pathway.

Finally, to fully evaluate the validity of this hypothesised model in the rat, it was essential to assess the effects of CNP and/or steroid hormones on the duration of meiotic arrest in cultured COCs. Interestingly in this study, the timing of GVBD initiation was modulated by the CNP and oestradiol in combination, and by CNP and progesterone in combination, following the 5 hour incubation. Furthermore, there was no effect of time on GVBD initiation. These results were inconsistent with previous reports (Zhang et al., 2010; Kawamura et al., 2011) and this effect is likely due to the supplementation of culture media with dipyradimole and rolipram. The addition of these phosphodiesterase inhibitors was probably not appropriate for studying the timing of meiotic resumption in cultured COCs, but for the gap junction assay was necessary to prevent spontaneous meiotic resumption which is known to occur in rat COCs after 1-2 hours of in vitro culture (Wert and Larsen, 1989). The aim of phosphodiesterase inhibitor supplementation in context of the gap junction assays was to maintain meiotic arrest and gap junction communication in these cultured COCs over time such that these COCs remained sensitive, in terms of gap junction activity, to the effects of the treatments. In this, and previous, studies supplementation with dipyradimole and rolipram was shown to maintain gap junction communication in cultured COCs but did not alter the timing of meiotic resumption (Campen, 2013). There is extensive evidence in mouse models and limited evidence from a pig model, that the presence of CNP reduces the incidence of meiotic resumption in a dose-dependent manner (Zhang et al., 2010, 2011; Kawamura et al., 2011; Hiradate et al., 2013) while using a range of doses that are equivalent to those used in this study $(1,10$ and $100 \mathrm{nM})$. However, in these studies COCs were cultured in media absent of phosphodiesterase inhibitors or supplemented with the broad spectrum phosphodiesterase inhibitor, IBMX, which is largely ineffective at maintaining meiotic arrest in rat oocytes (Bilodeau-Goeseels, 2011; Downs, 2011). 
Thus, in order to overcome the masking of treatment effects by the presence of phosphodiesterase inhibitors, a further experiment was carried out to assess solely the timing of meiotic resumption in COCs that were cultured in media without these phosphodiesterase inhibitors. Due to logistical constraints, only one treatment was selected to be tested in comparison to controls. Collectively, the treatment that showed the largest influence on the other parameters tested within this study was CNP and oestradiol combined. An incubation time of 5 hours was chosen to allow enough time for untreated COCs to initiate GVBD as well as allow the treatment to have an effect. In addition, the incubation time of 5 hours had previously been shown to be successful in observing modulation of GVBD timing by these treatments (Kawamura et al., 2011). This experiment showed that treatment with CNP and oestradiol decreased GVBD rate significantly compared to the control COCs. Moreover, an effect of time was observed when comparing GVBD rate in the control COCs. Subsequently, an orcein staining technique was used to confirm that preliminary assessment of meiotic resumption was justified in all of the oocytes that were stained as well. As a consequence of these results, supplementation of media with phosphodiesterase inhibitors was also excluded from the experiments that assessed treatment effects on the levels of cGMP within rat COCs.

In summary, this study provides further evidence that the aforementioned hypothesised model of regulation of the duration of meiotic arrest is relevant to the rat. While gap junction permeability was not increased by any of the treatments tested herein, there was sufficient gap junction communication to allow for transfer of molecules such as cGMP from the cumulus cells to the oocyte. This study also indicated that CGMP levels, using both direct and indirect measurements, may be increased in rat COCs in response to treatment with CNP and oestradiol. Correspondingly, oestradiol (with or without CNP) and possibly progesterone upregulated Npr2 mRNA expression in rat cumulus cells. Interestingly, Pde4d expression was complex and perhaps multi-faceted, however all treatments that contained CNP appeared to consistently stimulate Pde $4 d$ expression levels suggesting that an increase in cGMP levels via CNP stimulation results in an upregulation of Pde $4 d$ mRNA. This is likely to be part of a feed-back loop that regulates fluctuations in cGMP levels. Finally, this study confirms that CNP together with oestradiol prolongs the duration of meiotic arrest in rat COCs after 5 hours in culture. 
This study has highlighted the complexity and lack of knowledge surrounding the role phosphodiesterases in meiotic resumption and other pertinent phosphodiesterases may be involved in the regulation of meiotic resumption in rats. 


\section{Chapter 6: Conclusions and Future Directions}

Overall the results of this study indicate that while CNP and oestradiol did not increase gap junction permeability in rat COCs in vitro, it was possible that these treatments increased the production of cGMP, however this requires further investigation. Notably, this study confirmed the role of oestradiol in upregulating Npr2 expression and that treatment of rat COCs with CNP and oestradiol delayed meiotic resumption in vitro.

The gene expression study revealed a number of interesting results including a possible role for progesterone and CNP in the regulation Npr2 expression. In addition, Pde $4 d$ expression was shown to be highly variable and suggested a possible negative feedback loop as all treatments that included CNP, thus increasing intracellular cyclic nucleotide levels, also appeared to increase Pde4d expression levels.

While the results presented herein have been useful in evaluating the validity of the hypothesis, they have also raised a number of questions that warrant further investigation. Further studies to confirm the stimulatory action of CNP and oestradiol on cGMP levels in COCs are required. In addition, it would be particularly useful to identify whether these treatments increase cGMP levels in the cumulus cells which is then subsequently transferred into the oocyte as stipulated in the model. Another area for further investigation would be the effect of progesterone alone and in combination with CNP, on Npr2 mRNA expression levels. Unfortunately the logistics of the study described herein did not allow for an investigation into the effects of progesterone alone on Npr2 expression levels.

Despite this, the major limitation for this study was the unexpected effects of the phosphodiesterase inhibitors dipyradimole and rolipram on the duration of meiotic arrest in cultured COCs. Previous studies within our laboratory revealed that gap junction permeability was improved with the addition of these phosphodiesterase inhibitors (Campen, 2013). One strength of this study was that measurements of gap junction permeability, duration of meiotic arrest and gene expression levels were collected from the same individual $\mathrm{COC}$ so that these results could be directly compared. Unfortunately a weakness of this experimental design was that all these 
samples were cultured in the presence of phosphodiesterase inhibitors. Due to logistical constraints, it was not possible to assess the effects of all the treatment combinations (treatment and incubation times) on the duration of meiotic arrest without the influence of the phosphodiesterase inhibitors. This may provide further information about the effects of progesterone in this mechanism. Moreover, because rolipram is a PDE4-specific phosphodiesterase inhibitor, it would be worthwhile to investigate whether treatment with the phosphodiesterase inhibitors modulates the expression of $P d e 4 b$ and $P d e 4 d$.

In conclusion, the results of this study provide evidence that the hypothesised mechanism that regulates meiotic resumption in mice is also relevant in the rat. These results also provide an insight into the complexities of the regulation of meiotic arrest and indicate phosphodiesterases are likely to have a major role to play in this mechanism. 


\section{BIBLIOGRAPHY}

Abbey-Hosch, S.E., Smirnov, D., Potter, L.R., 2005. Differential regulation of NPRB/GC-B by protein kinase $C$ and calcium. Biochem. Pharmacol. 70, 686-694.

Ackert, C.L., Gittens, J.E.I., O’Brien, M.J., Eppig, J.J., Kidder, G.M., 2001. Intercellular communication via Connexin43 gap junctions is required for ovarian folliculogenesis in the mouse. Dev. Biol. 233, 258-270.

Agilent Technologies, 2009. Brilliant II SYBR® Green QPCR Master Mix, Instruction Manual.

Aktas, H., Leibfried-Rutledge, M.L., First, N.L., 2003. Meiotic state of bovine oocytes is regulated by interactions between cAMP, cumulus, and granulosa. Mol. Reprod. Dev. 65, 336-343.

Armstrong, D.T., Xia, P., Gannes, G. de, Tekpetey, F.R., Khamsi, F., 1996. Differential effects of insulin-like growth factor-I and follicle-stimulating hormone on proliferation and differentiation of bovine cumulus cells and granulosa cells. Biol. Reprod. 54, 331-338.

Bilodeau-Goeseels, S., 2011. Cows are not mice: The role of cyclic AMP, phosphodiesterases, and adenosine monophosphate-activated protein kinase in the maintenance of meiotic arrest in bovine oocytes. Mol. Reprod. Dev. 78, 734-743.

Bowles, J., Koopman, P., 2007. Retinoic acid, meiosis and germ cell fate in mammals. Development 134, 3401-3411.

Brankin, V., Mitchell, M.R.P., Webb, B., Hunter, M.G., 2003. Paracrine effects of oocyte secreted factors and stem cell factor on porcine granulosa and theca cells in vitro. Reprod. Biol. Endocrinol. RBE 1, 55.

Braw-Tal, R., 2002. The initiation of follicle growth: the oocyte or the somatic cells? Mol. Cell. Endocrinol. 187, 11-18.

Campen, K.A., 2013. Investigation of exposure to lifestyle and environmental factors on cumulus-oocyte complex function. PhD thesis, Victoria University of Wellington.

Carabatsos, M.J., Sellitto, C., Goodenough, D.A., Albertini, D.F., 2000. Oocytegranulosa cell heterologous gap junctions are required for the coordination of nuclear and cytoplasmic meiotic competence. Dev. Biol. 226, 167-179. 
Chiquoine, A.D., 1954. The identification, origin, and migration of the primordial germ cells in the mouse embryo. Anat. Rec. 118, 135-146.

Cho, W.K., Stern, S., Biggers, J.D., 1974. Inhibitory effect of dibutyryl cAMP on mouse oocyte maturation in vitro. J. Exp. Zool. 187, 383-386.

Conti, M., 2011. Phosphodiesterases and regulation of female reproductive function. Curr. Opin. Pharmacol. 11, 665-669.

Couse, J.F., Yates, M.M., Deroo, B.J., Korach, K.S., 2005. Estrogen receptor- $\beta$ is critical to granulosa cell differentiation and the ovulatory response to gonadotropins. Endocrinology 146, 3247-3262.

Crawford, J.L., McNatty, K.P., 2012. The ratio of growth differentiation factor 9: Bone morphogenetic protein 15 mRNA expression is tightly co-regulated and differs between species over a wide range of ovulation rates. Mol. Cell. Endocrinol. 348, 339-343.

DiLuigi, A., Weitzman, V.N., Pace, M.C., Siano, L.J., Maier, D., Mehlmann, L.M., 2008. Meiotic arrest in human oocytes is maintained by a Gs signalling pathway. Biol. Reprod. 78, 667-672.

Downs, S.M., 2011. Mouse versus rat: Profound differences in meiotic regulation at the level of the isolated oocyte. Mol. Reprod. Dev. 78, 778-794.

Drummond, A.E., 2006. The role of steroids in follicular growth. Reprod. Biol. Endocrinol. 4, 16.

Edson, M.A., Nagaraja, A.K., Matzuk, M.M., 2009. The mammalian ovary from genesis to revelation. Endocr. Rev. 30, 624-712.

Edwards, R.G., Tarkowski, A.K., McLaren, A., Peters, H., 1970. Are oocytes formed and used sequentially in the mammalian ovary? [and discussion]. Philos. Trans. R. Soc. Lond. B. Biol. Sci. 259, 103-106.

Ekart, J., McNatty, K., Hutton, J., Pitman, J., 2013. Ranking and selection of MII oocytes in human ICSI cycles using gene expression levels from associated cumulus cells. Hum. Reprod. 28, 2930-2942.

Eppig, J.J., Downs, S.M., 1987. The effect of hypoxanthine on mouse oocyte growth and development in vitro: Maintenance of meiotic arrest and gonadotropininduced oocyte maturation. Dev. Biol. 119, 313-321.

Eppig, J.J., Ward-Bailey, P.F., Coleman, D.L., 1985. Hypoxanthine and adenosine in murine ovarian follicular fluid: concentrations and activity in maintaining oocyte meiotic arrest. Biol. Reprod. 33, 1041-1049. 
Eppig, J.J., Wigglesworth, K., Pendola, F.L., 2002. The mammalian oocyte orchestrates the rate of ovarian follicular development. Proc. Natl. Acad. Sci. 99, 2890-2894.

Francis, S.H., Blount, M.A., Corbin, J.D., 2011. Mammalian cyclic nucleotide phosphodiesterases: Molecular mechanisms and physiological functions. Physiol. Rev. 91, 651-690.

Geister, K.A., Brinkmeier, M.L., Hsieh, M., Faust, S.M., Karolyi, I.J., Perosky, J.E., Kozloff, K.M., Conti, M., Camper, S.A., 2013. A novel loss-of-function mutation in Npr2 clarifies primary role in female reproduction and reveals a potential therapy for acromesomelic dysplasia, Maroteaux type. Hum. Mol. Genet. 22, 345-357.

Gilchrist, R.B., 2011. Recent insights into oocyte - follicle cell interactions provide opportunities for the development of new approaches to in vitro maturation. Reprod. Fertil. Dev. 23, 23.

Gilchrist, R.B., Lane, M., Thompson, J.G., 2008. Oocyte-secreted factors: regulators of cumulus cell function and oocyte quality. Hum. Reprod. Update 14, 159177.

Goff, A.K., Henderson, K.M., 1979. Changes in follicular fluid and serum concentrations of steroids in PMS treated immature rats following $\mathrm{LH}$ administration. Biol. Reprod. 20, 1153-1157.

Gutkowska, J., Jankowski, M., Sairam, M.R., Fujio, N., Reis, A.M., MukaddamDaher, S., Tremblay, J., 1999. Hormonal regulation of natriuretic peptide system during induced ovarian follicular development in the rat. Biol. Reprod. $61,162-170$.

Hayashi, M., McGee, E.A., Min, G., Klein, C., Rose, U.M., Van Duin, M., Hsueh, A.J., 1999. Recombinant growth differentiation factor-9 (GDF-9) enhances growth and differentiation of cultured early ovarian follicles. Endocrinology 140, 1236-1244.

Hild-Petito, S., Stouffer, R.L., Brenner, R.M., 1988. Immunocytochemical localization of estradiol and progesterone receptors in the monkey ovary throughout the menstrual cycle. Endocrinology 123, 2896-2905.

Hinckley, M., Vaccari, S., Horner, K., Chen, R., Conti, M., 2005. The G-proteincoupled receptors GPR3 and GPR12 are involved in cAMP signaling and maintenance of meiotic arrest in rodent oocytes. Dev. Biol. 287, 249-261. 
Hiradate, Y., Hoshino, Y., Tanemura, K., Sato, E., 2013. C-type natriuretic peptide inhibits porcine oocyte meiotic resumption. Zygote FirstView, 1-6.

Hirshfield, A.N., 1991. Development of follicles in the mammalian ovary. Int. Rev. Cytol. 124, 43-101.

Jankowski, M., Reis, A.M., Mukaddam-Daher, S., Dam, T.V., Farookhi, R., Gutkowska, J., 1997. C-type natriuretic peptide and the guanylyl cyclase receptors in the rat ovary are modulated by the estrous cycle. Biol. Reprod. $56,59-66$.

Jin, S.-L.C., Richard, F.J., Kuo, W.-P., D'Ercole, A.J., Conti, M., 1999. Impaired growth and fertility of cAMP-specific phosphodiesterase PDE4D-deficient mice. Proc. Natl. Acad. Sci. 96, 11998-12003.

Juneja, S.C., Barr, K.J., Enders, G.C., Kidder, G.M., 1999. Defects in the germ line and gonads of mice lacking connexin43. Biol. Reprod. 60, 1263-1270.

Kaji, E., Bornslaeger, E.A., Schultz, R.M., 1987. Inhibition of mouse oocyte cyclic AMP phosphodiesterase by steroid hormones: A possible mechanism for steroid hormone inhibition of oocyte maturation. J. Exp. Zool. 243, 489-493.

Kawamura, K., Cheng, Y., Kawamura, N., Takae, S., Okada, A., Kawagoe, Y., Mulders, S., Terada, Y., Hsueh, A.J.W., 2011. Pre-ovulatory LH/hCG surge decreases C-type natriuretic peptide secretion by ovarian granulosa cells to promote meiotic resumption of pre-ovulatory oocytes. Hum. Reprod. 26, 3094-3101.

Kiyosu, C., Tsuji, T., Yamada, K., Kajita, S., Kunieda, T., 2012. NPPC/NPR2 signaling is essential for oocyte meiotic arrest and cumulus oophorus formation during follicular development in the mouse ovary. Reproduction 144, 187-193.

Koller, K.J., Lowe, D.G., Bennett, G.L., Minamino, N., Kangawa, K., Matsuo, H., Goeddel, D.V., 1991. Selective activation of the B natriuretic peptide receptor by C-type natriuretic peptide (CNP). Science 252, 120-123.

Life Technologies, 2010. Acetoxymethyl (AM) and Acetate Esters. http://tools.lifetechnologies.com/content/sfs/manuals/g002.pdf

Livak, K.J., Schmittgen, T.D., 2001. Analysis of relative gene expression data using real-time quantitative PCR and the 2- $\triangle \Delta C T$ method. Methods $25,402-408$. 
Lucidi, P., Bernabò, N., Turriani, M., Barboni, B., Mattioli, M., 2003. Cumulus cells steroidogenesis is influenced by the degree of oocyte maturation. Reprod. Biol. Endocrinol. RBE 1, 45.

Lydon, J.P., DeMayo, F.J., Funk, C.R., Mani, S.K., Hughes, A.R., Montgomery, C.A., Shyamala, G., Conneely, O.M., O’Malley, B.W., 1995. Mice lacking progesterone receptor exhibit pleiotropic reproductive abnormalities. Genes Dev. 9, 2266-2278.

Mayerhofer, A., Garfield, R.E., 1995. Immunocytochemical analysis of the expression of gap junction protein connexin 43 in the rat ovary. Mol. Reprod. Dev. 41, 331-338.

McNatty, K.P., Lun, S., Heath, D.A., Ball, K., Smith, P., Hudson, N.L., McDiarmid, J., Gibb, M., Henderson, K.M., 1986. Differences in ovarian activity between booroola $\mathrm{X}$ merino ewes which were homozygous, heterozygous and noncarriers of a major gene influencing their ovulation rate. J. Reprod. Fertil. 77, 193-205.

MehImann, L.M., 2005a. Stops and starts in mammalian oocytes: Recent advances in understanding the regulation of meiotic arrest and oocyte maturation. Reproduction 130, 791-799.

Mehlmann, L.M., 2005b. Oocyte-specific expression of Gpr3 is required for the maintenance of meiotic arrest in mouse oocytes. Dev. Biol. 288, 397-404. Mehlmann, L.M., Jones, T.L.Z., Jaffe, L.A., 2002. Meiotic arrest in the mouse follicle maintained by a $\mathrm{G}(\mathrm{s})$ protein in the oocyte. Science $297,1343-5$.

Nakamura, Y., Yamagata, Y., Sugino, N., Takayama, H., Kato, H., 2002. Nitric oxide inhibits oocyte meiotic maturation. Biol. Reprod. 67, 1588-1592.

Norris, R.P., Ratzan, W.J., Freudzon, M., Mehlmann, L.M., Krall, J., Movsesian, M.A., Wang, H., Ke, H., Nikolaev, V.O., Jaffe, L.A., 2009. Cyclic GMP from the surrounding somatic cells regulates cyclic AMP and meiosis in the mouse oocyte. Development 136, 1869-1878.

Noubani, A., Farookhi, R., Gutkowska, J., 2000. B-Type natriuretic peptide receptor expression and activity are hormonally regulated in rat ovarian cells. Endocrinology 141, 551-559.

Park, J.-Y., Richard, F., Chun, S.-Y., Park, J.-H., Law, E., Horner, K., Jin, S.-L.C., Conti, M., 2003. Phosphodiesterase regulation is critical for the differentiation 
and pattern of gene expression in granulosa cells of the ovarian follicle. Mol. Endocrinol. 17, 1117-1130.

Park, O.-K., Mayo, K.E., 1991. Transient expression of progesterone receptor messenger RNA in ovarian granulosa cells after the preovulatory luteinizing hormone surge. Mol. Endocrinol. 5, 967-978.

Pelletier, G., Labrie, C., Labrie, F., 2000. Localization of oestrogen receptor alpha, oestrogen receptor beta and androgen receptors in the rat reproductive organs. J. Endocrinol. 165, 359-370.

Peters, H., Byskov, A.G., Himelstein-Braw, R., Faber, M., 1975. Follicular growth: the basic event in the mouse and human ovary. J. Reprod. Fertil. 45, 559-566.

Pincus, G., Enzmann, E.V., 1935. The comparative behavior of mammalian eggs in vivo and in vitro I. The activation of ovarian eggs. J. Exp. Med. 62, 665-675.

Richard, F.J., Tsafriri, A., Conti, M., 2001. Role of phosphodiesterase type 3A in rat oocyte maturation. Biol. Reprod. 65, 1444-1451.

Richards, J.S., Rolfes, A.I., 1980. Hormonal regulation of cyclic AMP binding to specific receptor proteins in rat ovarian follicles. Characterization by photoaffinity labelling. J. Biol. Chem. 255, 5481-5489.

Richardson, S.J., Senikas, V., Nelson, J.F., 1987. Follicular depletion during the menopausal transition: Evidence for accelerated loss and ultimate exhaustion. J. Clin. Endocrinol. Metab. 65, 1231-1237.

Robinson, J.W., Zhang, M., Shuhaibar, L.C., Norris, R.P., Geerts, A., Wunder, F., Eppig, J.J., Potter, L.R., Jaffe, L.A., 2012. Luteinizing hormone reduces the activity of the NPR2 guanylyl cyclase in mouse ovarian follicles, contributing to the cyclic GMP decrease that promotes resumption of meiosis in oocytes. Dev. Biol. 366, 308-316.

Rodgers, R.J., Irving-Rodgers, H.F., 2010. Formation of the ovarian follicular antrum and follicular fluid. Biol. Reprod. 82, 1021-1029.

Sasseville, M., Gagnon, M.-C., Guillemette, C., Sullivan, R., Gilchrist, R.B., Richard, F.J., 2009. Regulation of gap junctions in porcine cumulus-oocyte complexes: contributions of granulosa cell contact, gonadotropins, and lipid rafts. Mol. Endocrinol. 23, 700-710.

Sato, Y., Cheng, Y., Kawamura, K., Takae, S., Hsueh, A.J.W., 2012. C-Type natriuretic peptide stimulates ovarian follicle development. Mol. Endocrinol. 26, 1158-1166. 
Sawyer, H.R., Smith, P., Heath, D.A., Juengel, J.L., Wakefield, S.J., McNatty, K.P., 2002. Formation of ovarian follicles during fetal development in sheep. Biol. Reprod. 66, 1134-1150.

Scaramuzzi, R., Adams, N., Baird, D., Campbell, B., Downing, J., Findlay, J., Henderson, K., Martin, G., McNatty, K., McNeilly, A., Tsonis, C., 1993. A model for follicle selection and the determination of ovulation rate in the ewe. Reprod. Fertil. Dev. 5, 459-478.

Sela-Abramovich, S., Edry, I., Galiani, D., Nevo, N., Dekel, N., 2006. Disruption of gap junctional communication within the ovarian follicle induces oocyte maturation. Endocrinology 147, 2280-2286.

Sela-Abramovich, S., Galiani, D., Nevo, N., Dekel, N., 2008. Inhibition of rat oocyte maturation and ovulation by nitric oxide: Mechanism of action. Biol. Reprod. 78, 1111-1118.

Sellitti, D.F., Koles, N., Mendonça, M.C., 2011. Regulation of C-type natriuretic peptide expression. Peptides 32, 1964-1971.

Shen, W., Ahmad, F., Hockman, S., Ma, J., Omi, H., Raghavachari, N., Manganiello, V., 2010. Female infertility in PDE3A -/- mice: Polo-like kinase 1 (Plk1) may be a target of Protein Kinase $A$ (PKA) and involved in meiotic arrest of oocytes from PDE3A -/- mice. Cell Cycle 9, 4720-4734.

Simon, A.M., Goodenough, D.A., Li, E., Paul, D.L., 1997. Female infertility in mice lacking connexin 37. Nature 385, 525-529.

Sirard, M.A., 2001. Resumption of meiosis: mechanism involved in meiotic progression and its relation with developmental competence. Theriogenology 55, 1241-1254.

Sirard, M.A., 2011. Follicle environment and quality of in vitro matured oocytes. J. Assist. Reprod. Genet. 28, 483-8.

Sugiura, K., Eppig, J.J., 2005. Society for Reproductive Biology Founders' Lecture 2005. Control of metabolic cooperativity between oocytes and their companion granulosa cells by mouse oocytes. Reprod Fertil Dev 17, 667674.

Thomas, R.E., Armstrong, D.T., Gilchrist, R.B., 2002. Differential effects of specific phosphodiesterase isoenzyme inhibitors on bovine oocyte meiotic maturation. Dev. Biol. 244, 215-225. 
Thomas, R.E., Armstrong, D.T., Gilchrist, R.B., 2004. Bovine cumulus cell-oocyte gap junctional communication during in vitro maturation in response to manipulation of cell-specific cyclic adenosine 3', 5'-monophosophate levels. Biol. Reprod. 70, 548-556.

Törnell, J., Billig, H., Hillensjö, T., 1990. Resumption of rat oocyte meiosis is paralleled by a decrease in guanosine 3',5'-cyclic monophosphate (cGMP) and is inhibited by microinjection of cGMP. Acta Physiol. Scand. 139, 511517.

Tortora, G.J., 2003. Principles of anatomy and physiology, 10th ed. Wiley, New York.

Tripathi, A., Kumar, K.V.P., Chaube, S.K., 2010. Meiotic cell cycle arrest in mammalian oocytes. J. Cell. Physiol. 223, 592-600.

Tsafriri, A., Channing, C.P., 1975. An Inhibitory influence of granulosa cells and follicular fluid upon porcine oocyte meiosis in vitro. Endocrinology 96, 922927.

Tsafriri, A., Chun, S.-Y., Zhang, R., Hsueh, A.J.W., Conti, M., 1996. Oocyte maturation involves compartmentalization and opposing changes of cAMP levels in follicular somatic and germ cells: Studies using selective phosphodiesterase inhibitors. Dev. Biol. 178, 393-402.

Tsuji, T., Kiyosu, C., Akiyama, K., Kunieda, T., 2012. CNP/NPR2 signaling maintains oocyte meiotic arrest in early antral follicles and is suppressed by EGFRmediated signaling in preovulatory follicles. Mol. Reprod. Dev. 79, 795-802.

Vaccari, S., Horner, K., Mehlmann, L.M., Conti, M., 2008. Generation of mouse oocytes defective in cAMP synthesis and degradation: Endogenous cyclic AMP is essential for meiotic arrest. Dev. Biol. 316, 124-134.

Vaccari, S., Weeks, J.L., Hsieh, M., Menniti, F.S., Conti, M., 2009. Cyclic GMP signaling is involved in the luteinizing hormone-dependent meiotic maturation of mouse oocytes. Biol. Reprod. 81, 595-604.

Van den Hurk, R., Zhao, J., 2005. Formation of mammalian oocytes and their growth, differentiation and maturation within ovarian follicles. Theriogenology 63, 1717-1751.

Vanderhyden, B.C., Cohen, J.N., Morley, P., 1993. Mouse oocytes regulate granulosa cell steroidogenesis. Endocrinology 133, 423-426. 
Veitch, G.I., Gittens, J.E.I., Shao, Q., Laird, D.W., Kidder, G.M., 2004. Selective assembly of connexin37 into heterocellular gap junctions at the oocyte/granulosa cell interface. J. Cell Sci. 117, 2699-2707.

Webb, R.J., Marshall, F., Swann, K., Carroll, J., 2002. Follicle-stimulating hormone induces a gap junction-dependent dynamic change in cAMP and protein kinase A in mammalian oocytes. Dev. Biol. 246, 441-454.

Wert, S.E., Larsen, W.J., 1989. Meiotic resumption and gap junction modulation in the cultured rat cumulus-oocyte complex. Gamete Res. 22, 143-162.

Westergaard, L., Christensen, I.J., McNatty, K.P., 1986. Steroid levels in ovarian follicular fluid related to follicle size and health status during the normal menstrual cycle in women. Hum. Reprod. Oxf. Engl. 1, 227-232.

Whitaker, M., 1996. Control of meiotic arrest. Rev. Reprod. 1, 127-135.

Yang, M.Y., Fortune, J.E., 2008. The capacity of primordial follicles in fetal bovine ovaries to initiate growth in vitro develops during mid-gestation and is associated with meiotic arrest of oocytes. Biol. Reprod. 78, 1153-1161.

Zamboni, L., BéZard, J., MauléOn, P., 1979. The role of the mesonephros in the development of the sheep fetal ovary. Ann. Biol. Anim. Biochim. Biophys. 19, 1153-1178.

Zhang, M., Su, Y.-Q., Sugiura, K., Wigglesworth, K., Xia, G., Eppig, J.J., 2011. Estradiol promotes and maintains cumulus cell expression of natriuretic peptide receptor 2 (NPR2) and meiotic arrest in mouse oocytes in vitro. Endocrinology 152, 4377-4385.

Zhang, M., Su, Y.-Q., Sugiura, K., Xia, G., Eppig, J.J., 2010. Granulosa cell ligand NPPC and its receptor NPR2 maintain meiotic arrest in mouse oocytes. Science 330, 366-369.

Zhang, M., Xia, G., 2011. Hormonal control of mammalian oocyte meiosis at diplotene stage. Cell. Mol. Life Sci. 